\title{
Maxwell-Stefan model of multicomponent ion transport inside a monolayer Nafion membrane for intensified chlor-alkali electrolysis
}

\author{
R. R. Sijabat ${ }^{1} \cdot$ M. T. de Groot ${ }^{1,2} \cdot$ S. Moshtarikhah ${ }^{1} \cdot$ J. van der Schaaf ${ }^{1}$ (D)
}

Received: 23 August 2018 / Accepted: 22 December 2018 / Published online: 9 February 2019

(c) The Author(s) 2019

\begin{abstract}
A mathematical model based on a generalized Maxwell-Stefan equation has been developed to describe multicomponent ion and water transport inside a cation-exchange membrane. This model has been validated using experimental data and has been used to predict concentration profiles, membrane potential drop, and transport numbers of ions and water for the chlor-alkali process at increased current densities. Several improvements have been made to previously developed MaxwellStefan models. In our model, the generalized Maxwell-Stefan equation is written in terms of concentration instead of mole fraction and the fixed group (membrane) concentration is assumed to be constant. We have adapted the Augmented matrix

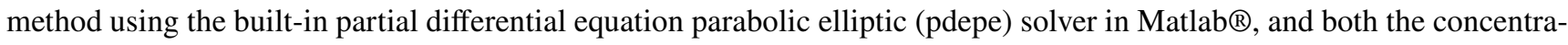
tion and the electrical potential gradients have been solved simultaneously. The boundary conditions are determined with the Donnan equilibrium at the membrane-solution interface. We have also employed semi-empirical correlations to define the Maxwell-Stefan diffusivities inside the membrane. For the bulk diffusivities, we applied the correlations for the concentrated solution instead of the values at infinite dilution. With the diffusivities presented in this work, the model shows a better fit to the experimental data than with previously reported fitted diffusivities. Prediction of the sodium transport number and water transport number is generally good, whereas the deviations with regard to membrane potential might also be related to issues with the experimental data. The model predicts an increase in both sodium and water transport numbers at increased current density operation of chlor-alkali production.
\end{abstract}

\section{Graphical abstract}

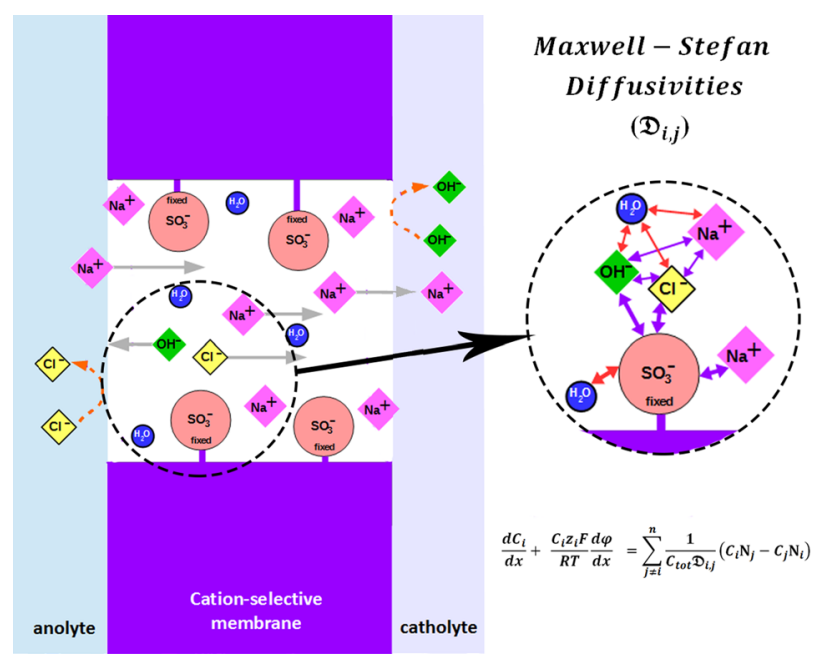

Extended author information available on the last page of the article 
Keywords Multicomponent ion transport - Maxwell-Stefan diffusivities · Donnan equilibrium · High current density ·

Membrane electrolysis

\section{Lits of symbols}

\section{Latin symbols}

$\mathrm{C}_{\mathrm{i}} \quad$ Concentration of species $\mathrm{i}\left(\mathrm{mol} \mathrm{m}^{-3}\right)$

C Concentration of the negative ion in Eq. (9) $\left(\mathrm{mol} \mathrm{cm}{ }^{-3}\right)$

$\mathrm{C}_{0} \quad$ Bulk concentration in Eq. (9) $\left(\mathrm{mol} \mathrm{cm}^{-3}\right)$

$\mathfrak{D}_{i, j}^{\mathrm{m}} \quad$ Maxwell-Stefan diffusivities inside the membrane $\left(\mathrm{m}^{2} \mathrm{~s}^{-1}\right)$

$\mathfrak{D}_{\mathrm{i}, \mathrm{w}}^{0} \quad$ Maxwell-Stefan diffusivities in the diluted bulk solution $\left(\mathrm{m}^{2} \mathrm{~s}^{-1}\right)$

$\mathfrak{D}_{\mathrm{i}, \mathrm{w}}^{\mathrm{b}} \quad$ Maxwell-Stefan diffusivities (interaction of ion-water) for concentrated bulk solution in Eqs. (5-8) $\left(\mathrm{cm}^{2} \mathrm{~s}^{-1}\right)$

$\mathfrak{D}_{+,-}^{\mathrm{b}} \quad$ Maxwell-Stefan diffusivities (interaction of negative-positive ion) for concentrated bulk solution in Eq. (9) $\left(\mathrm{cm}^{2} \mathrm{~s}^{-1}\right)$

EW Equivalent weight $\left(\mathrm{g} \mathrm{mol}^{-1}\right)$

$f_{\mathrm{e}} \quad$ Weight fraction of electrolyte in the ion cluster (-)

$f_{\mathrm{m}} \quad$ Weight fraction of fixed ionic groups in the ion cluster (-)

F Faraday constant $\left(\mathrm{C} \mathrm{mol}^{-1}\right)$

$\mathrm{G} \quad$ Correction for idealized theory in Eq. (9) $\left(\mathrm{K}^{3 / 2} \mathrm{M}^{-1 / 2}\right)$

I Current density $\left(\mathrm{A} \mathrm{m}^{-2}\right)$

$\mathrm{K} \quad$ Donnan equilibrium constant (-)

K Kelvin

$l_{\mathrm{i}}^{0} \quad$ Limiting equivalent conductivity $\left(\mathrm{cm}^{2} \mathrm{Ohm}^{-1}\right.$ $\mathrm{mol}^{-1}$ )

M Mol liter ${ }^{-1}$

Mw Molecular weight $\left(\mathrm{g} \mathrm{mol}^{-1}\right)$

$N_{\mathrm{i}} \quad$ Molar flux of species i $\left(\mathrm{mol} \mathrm{m}^{-2} \mathrm{~s}^{-1}\right)$

$\mathrm{P} \quad$ Pressure $(\mathrm{Pa})$

q Constant defined in Eq. (10) (-)

Q, R, S, T Fitting constant for density correlations defined in Eqs. (21-30) (-)

$\mathrm{R} \quad$ Gas constant $\left(\mathrm{J} \mathrm{mol}^{-1} \mathrm{~K}^{-1}\right)$

$\mathrm{t} \quad$ Time (s)

$\mathrm{t}_{\mathrm{i}} \quad$ Ion transport number (-)

$\mathrm{T} \quad$ Temperature $(\mathrm{K})$

$T_{\mathrm{c}} \quad$ Temperature $\left({ }^{\circ} \mathrm{C}\right)$

$W \quad$ Weight percentage (wt $\%)$

$W_{\mathrm{w}} \quad$ Membrane water content (wt\% dry polymer)

W Water

$X \quad$ Mole fraction (-)

$\nu_{\mathrm{i}} \quad$ Valence number (-)

$\bar{V}_{\mathrm{i}} \quad$ Partial molar volume $\left(\mathrm{m}^{3} \mathrm{~mol}^{-1}\right)$

$\gamma_{\mathrm{i}} \quad$ Activity coefficient (-)

$\begin{array}{ll}z_{\mathrm{i}} & \text { Ionic charge }(-) \\ z & \text { Dimensionless length }(-)\end{array}$

\section{Greek symbols}

$\delta \quad$ Membrane thickness (m)

$\varphi \quad$ Electrical potential (V)

$\rho \quad$ Density $\left(\mathrm{g} \mathrm{cm}^{-3}\right)$

$\mu \quad$ Chemical potential $\left(\mathrm{J} \mathrm{mol}^{-1}\right)$

$\eta \quad$ Electrochemical potential $\left(\mathrm{J} \mathrm{mol}^{-1}\right)$

$\varepsilon_{\text {void }} \quad$ Void fraction (-)

$\tau \quad$ Tortuosity (-)

\section{Superscript and subscript}

A Anolyte

c Centigrade

C Catholyte

e Electrolyte

exp. Experiment

i Species

int Interface

1 Left

m Membrane

neg Negative

pos Positive

$r \quad$ Right

ref Reference

s Solution phase

tot Total

w Water

\section{Introduction}

Renewable energy sources are increasingly available as an alternative electricity source for large-scale electrolysis processes, such as chlorine production and water electrolysis. Due to the intermittent nature of the renewables, it is crucial to develop new intensified electrolysis cells that can be operated with high flexibility. This can be achieved by increasing the maximum current density. For the chlor-alkali process, an ambitious target would be $30 \mathrm{kA} \mathrm{m}^{-2}$ (currently the process is limited to $7 \mathrm{kA} \mathrm{m}^{-2}$ ) [1].

A key aspect of operation at higher current densities is the membrane performance. Unfortunately, the information on membrane performance at high current densities remains scarce. Ion transport across a membrane under current load is not completely understood despite the fact that there have been several attempts to model the behavior by either using Maxwell-Stefan (MS) or Nernst-Planck (NP) models [2-8]. The Nernst-Planck approach assumes an ideal solution and neglects ion-ion interactions. This model is known 
to be valid for dilute ionic systems $[9,10]$, but chlor-alkali electrolysis involves highly concentrated solutions, typically around $5 \mathrm{M}$ sodium chloride $(\mathrm{NaCl})$ and $10 \mathrm{M}$ sodium hydroxide $(\mathrm{NaOH})$ [11]. In this case, the Maxwell-Stefan is considered more reliable since the interactions of different components and the non-ideal solutions are taken into account [9, 12-14]. Moreover, the Maxwell-Stefan approach includes the water transport via the solvent-ion interactions, whereas the Nernst-Planck model has to introduce a separate equation (i.e., the Schlögl equation) to account for the water transport $[10,15]$.

The process intensification of the chlor-alkali process would benefit from a mathematical model that can predict the membrane performance. Up to this date, only Van der Stegen et al. [2] have developed a Maxwell-Stefan model for the chlor-alkali system. However, this model has some limitations. It was derived in mole fraction which assumed that the total concentration is known. The ionic fixed groups of the membrane were regarded as one of the mobile components in the aqueous mixture to obtain convergence, whereas the fixed charge group concentration is generally considered to be constant inside the membrane. This model has also simplified the calculation of the membrane potential gradient by neglecting the concentration gradient and by using Ohm's law to derive the potential gradient explicitly. The neutrality condition is broken by this simplification, which has been numerically proven during the investigation of the extended Nernst-Planck model [8].

The main drawback in applying the Maxwell-Stefan approach is the lack of reliable data on diffusivities at high concentrations. The Maxwell-Stefan diffusivities $\left(\mathfrak{D}_{i, j}\right)$ are required for the interaction between the components in a mixture. In a mixture with $n$ components, the number of Maxwell-Stefan diffusivities should be $0.5 \times n \times(n-1)$ based on the Onsager relations [16]. The chlor-alkali system contains at least five components $\left(\mathrm{Na}^{+}, \mathrm{Cl}^{-}, \mathrm{OH}^{-}, \mathrm{H}_{2} \mathrm{O}\right.$, and $\left.-\mathrm{SO}_{3}{ }^{-}\right)$and hence requires ten binary diffusivities.

Wesselingh et al. [17] proposed that the diffusivities inside the membrane can be related to the diffusivities in the bulk using the tortuosity factor $(\tau)$, (Eq. 1). $\mathfrak{D}_{\mathrm{i}, \mathrm{w}}^{0}$ is the diffusion coefficient in infinitely diluted aqueous solution (Eq. 2). The values for $\mathfrak{D}_{\mathrm{i}, \mathrm{w}}^{0}$ at $25^{\circ} \mathrm{C}$ and $90^{\circ} \mathrm{C}$ are given in Table 1 for sodium, chloride, and hydroxide in water. Kraaijeveld et al. [4] proposed a correlation for the diffusivity of positive ions and sulfonate groups in the membrane $\left(\mathfrak{D}_{+, \mathrm{SO}_{3}^{-}}^{\mathrm{m}}\right)$ in Eq. (3). As can be seen from the equation, it is suggested that this diffusivity is related to the diffusivity of the same ion with water in the membrane. The diffusivity of negative ions and sulfonate groups in the membrane were fitted in the model based on the experimental data of dialysis.

$\mathfrak{D}_{\mathrm{i}, \mathrm{w}}^{\mathrm{m}}=\mathfrak{D}_{\mathrm{i}, \mathrm{w}}^{0} \tau^{-1}=\varepsilon_{\text {void }}^{1.5} \mathfrak{D}_{\mathrm{i}, \mathrm{w}}^{0}$
$\mathfrak{D}_{\mathrm{i}, \mathrm{w}}^{0}=l_{\mathrm{i}}^{0}\left(R T / z_{\mathrm{i}} F^{2}\right)$

$\mathfrak{D}_{+, \mathrm{SO}_{3}^{-}}^{\mathrm{m}}=0.1 \varepsilon_{\text {void }}^{1.5} \mathfrak{D}_{\mathrm{i}, \mathrm{w}}^{0}$.

According to Van der Stegen et al. [2], the low values of diffusivities from the correlations of Wesselingh et al. resulted in an unreasonably high membrane potential for the chloralkali system. Instead they opted for estimating diffusivities using a sensitivity analysis based on four output parameters in the chlor-alkali process: current efficiency, cell potential, relative water transport number, and the chloride concentration in caustic (catholyte solution). They assumed that the membrane potential was about $15 \%$ of the total cell potential. The input parameters for the model were anolyte $(\mathrm{NaCl})$ and catholyte $(\mathrm{NaOH})$ concentration, membrane thickness, membrane equivalent weight (EW), current density, temperature and initial values of diffusivities. They excluded four out of ten Maxwell-Stefan diffusivities by choosing high values $\left(1 \times 10^{-8} \mathrm{~m}^{2}\right.$ $\mathrm{s}^{-1}$ ) to neglect the interaction between these components. They indicated that the values of the diffusivities are a function of current density (I) as given in Eq. (4), in which $\mathfrak{D}_{i, j_{\text {ref, exp }}}^{\text {is the }}$ fitted Maxwell-Stefan diffusivity at $4 \mathrm{kA} \mathrm{m}^{-2}$ listed in Table 1 .

$\mathfrak{D}_{i, j}^{\mathrm{m}}=\left(2.4423 \times 10^{-4} I+0.037\right) \times \mathfrak{D}_{i, j_{\text {ref, exp }}}^{\mathrm{m}}$.

Other groups have looked at diffusivities in ion-exchange membranes for other systems than chlor-alkali. Visser et al. [3] encountered a similar problem with the low values of diffusivities using the semi-empirical equations of Wesselingh et al. Unlike Van der Stegen et al., they investigated the interactions of different electrolytes: $\mathrm{HCl}, \mathrm{H}_{2} \mathrm{SO}_{4}, \mathrm{NaCl}, \mathrm{NaOH}$, and $\mathrm{Na}_{2} \mathrm{SO}_{4}$. The diffusivities were fitted from several partial diffusion experiments: diffusion dialysis (salt diffusion flux and osmotic water flux), electro-osmotic, membrane resistance, pressure driven volume flow, and electrodialysis. They performed in total 26 experiments at $25{ }^{\circ} \mathrm{C}$ for a Nafion 450 membrane to define 21 binary diffusivities. The experiments used current densities from 0 to $1 \mathrm{kA} \mathrm{m}^{-2}$. The diffusivity values for $\mathrm{NaCl}$ and $\mathrm{NaOH}$ in the membrane are listed in Table 1. Despite their concern about low diffusivity issues from the semi-empirical equation, they applied Eq. (1) to estimate the chloride and hydroxide interaction with water inside the membrane $\left(\mathfrak{D}_{\mathrm{OH}^{-}, \mathrm{w}}^{\mathrm{m}}, \mathfrak{D}_{\mathrm{Cl}^{-}, \mathrm{w}}^{\mathrm{m}}\right)$. It is observed in Table 1 that the value of the binary diffusivities of sodium and hydroxide $\left(\mathfrak{D}_{\mathrm{Na}^{+}, \mathrm{OH}^{-}}^{\mathrm{m}}=100 \times 10^{-10} \mathrm{~m}^{2} \mathrm{~s}^{-1}\right)$ is remarkably different from the diffusivities of sodium and chloride $\left(\mathfrak{D}_{\mathrm{Na}^{+}, \mathrm{Cl}^{-}}^{\mathrm{m}}=0.580 \times 10^{-10} \mathrm{~m}^{2} \mathrm{~s}^{-1}\right)$, for which no explanation was given. It is important to note that they have excluded the Donnan potential as the boundary condition because of the convergence issue in the model. The co-ion concentration inside the membrane was estimated based on the algebraic 
Table 1 Fitted values of Maxwell-Stefan diffusivities in $10^{-10}\left(\mathrm{~m}^{2} \mathrm{~s}^{-1}\right)$ and the values of the diffusion coefficients at infinite dilution in the bulk using Eq. (2)

\begin{tabular}{|c|c|c|c|c|}
\hline \multirow[t]{2}{*}{ Component pair } & \multirow{2}{*}{$\begin{array}{l}\text { Van der Stegen et al. [2] } \\
\text { Chlor-alkali electrolysis } \\
\text { at } 4 \mathrm{kA} \mathrm{m}^{-2} \\
\text { Nafion (sulfonate part); } \\
\mathrm{EW}=1015 \\
\text { Model fitted } \\
\mathrm{T}=90^{\circ} \mathrm{C}\end{array}$} & \multirow{2}{*}{$\begin{array}{l}\text { Visser et al. [3] } \\
\text { Electrodialysis up to } 1 \mathrm{kA} \\
\mathrm{m}^{-2} \\
\text { Nafion } 450 ; \mathrm{EW}=1100 \\
\text { Model fitted } \\
\mathrm{T}=25^{\circ} \mathrm{C}\end{array}$} & \multicolumn{2}{|c|}{$\begin{array}{l}\text { Infinite dilution in the bulk } \\
\mathfrak{D}_{\mathrm{i}, \mathrm{w}}^{0} \\
\left(10^{-10} \mathrm{~m}^{2} \mathrm{~s}^{-1}\right)\end{array}$} \\
\hline & & & $25^{\circ} \mathrm{C}$ & $90^{\circ} \mathrm{C}$ \\
\hline $\mathfrak{D}_{\mathrm{Na}^{+}, \mathrm{w}}^{\mathrm{m}}$ & 11 & 5.14 & 13.3 & 43.6 \\
\hline $\mathfrak{D}_{\mathrm{Cl}^{-}, \mathrm{w}}^{\mathrm{m}}$ & $100^{\mathrm{b}}$ & $6.23^{\mathrm{a}}$ & 20.3 & 63.0 \\
\hline $\mathfrak{D}_{\mathrm{OH}^{-}, \mathrm{w}}^{\mathrm{m}}$ & 10 & $16.2^{\mathrm{a}}$ & 53.0 & 135 \\
\hline $\mathfrak{D}_{\mathrm{SO}_{3}^{-}, \mathrm{w}}^{\mathrm{m}}$ & 10 & 7.92 & & \\
\hline $\mathfrak{D}_{\mathrm{Na}^{+}, \mathrm{SO}_{3}^{-}}^{\mathrm{m}}$ & 3 & 2.26 & & \\
\hline $\mathfrak{D}_{\mathrm{Cl}^{-}, \mathrm{SO}_{3}^{-}}^{\mathrm{m}}$ & 0.1 & 0.169 & & \\
\hline $\mathfrak{D}_{\mathrm{OH}^{-}, \mathrm{SO}_{3}^{-}}^{\mathrm{m}}$ & $100^{\mathrm{b}}$ & 1.58 & & \\
\hline $\mathfrak{D}_{\mathrm{Na}^{+}, \mathrm{Cl}^{-}}^{\mathrm{m}}$ & $100^{\mathrm{b}}$ & 0.580 & & \\
\hline $\mathfrak{D}_{\mathrm{Na}^{+}, \mathrm{OH}^{-}}^{\mathrm{m}}$ & 10 & 100 & & \\
\hline $\mathfrak{D}_{\mathrm{OH}^{-}, \mathrm{Cl}^{-}}^{\mathrm{m}}$ & $100^{\mathrm{b}}$ & Not available & & \\
\hline
\end{tabular}

${ }^{\mathrm{a} C a l c u l a t e d}$ from Eq. (1)

${ }^{b}$ Effectively no friction between the components relations as a function of the external composition instead of the Donnan potential.

Chapman et al. [18] investigated Maxwell-Stefan diffusivities for concentrated electrolyte systems and made correlations to relate the diffusivities for high concentrations to diffusivities at infinite dilution as given in Eqs. (5-8). The interaction of negative and positive ions increases substantially with increasing concentration as shown in Eq. (9). The value of $q$ in Eq. (9) is defined in Eq. (10). $C$ is the concentration of the negative ion and $C_{0}$ represents the bulk concentration. $G$ (in $\mathrm{K}^{3 / 2} \mathrm{M}^{-1 / 2}$ ) is considered to be a correction for the idealized theory. It is strongly related to the concentration and the type of electrolyte. There was no systematic trend found for the effect of the temperature. Sodium chloride of $5 \mathrm{M}$ at $50{ }^{\circ} \mathrm{C}$ has a $G$ value of $979 \mathrm{~K}^{3 / 2} \mathrm{M}^{-1 / 2}$. The concentration of sodium hydroxide investigated is limited to $1.5 \mathrm{M}$ with the temperature at $25^{\circ} \mathrm{C}$, which has the value of $2606 \mathrm{~K}^{3 / 2} \mathrm{M}^{-1 / 2}$. For the high concentration above $3 \mathrm{M}$, the average value for uni-univalent electrolyte is reported to be $3000 \pm 1000 \mathrm{~K}^{3 / 2} \mathrm{M}^{-1 / 2}$.

$$
\begin{aligned}
\mathfrak{D}_{\mathrm{Na}^{+}, \mathrm{w}(\mathrm{NaCl})}^{\mathrm{b}}= & \mathfrak{D}_{\mathrm{Na}^{+}, \mathrm{w}}^{0}-1.798 \times 10^{-7} \times C_{\mathrm{NaCl}}^{1 / 2}-1.159 \times 10^{-6} \\
& \times C_{\mathrm{NaCl}}-6.288 \times 10^{-7} \times C_{\mathrm{NaCl}}^{3 / 2}+2.415 \times 10^{-7} \\
& \times C_{\mathrm{NaCl}}^{2}
\end{aligned}
$$

$$
\begin{aligned}
\mathfrak{D}_{\mathrm{Cl}}^{\mathrm{b}, \mathrm{w}(\mathrm{NaCl})} & =\mathfrak{D}_{\mathrm{Na}^{+}, \mathrm{w}}^{0}+3.022 \times 10^{-6} \times C_{\mathrm{NaCl}}^{1 / 2}-3.064 \times 10^{-6} \\
& \times C_{\mathrm{NaCl}}-6.230 \times 10^{-7} \times C_{\mathrm{NaCl}}^{3 / 2}+2.508 \times 10^{-7} \\
& \times C_{\mathrm{NaCl}}^{2}
\end{aligned}
$$

$$
\begin{aligned}
\mathfrak{D}_{\mathrm{Na}^{+}, \mathrm{w}(\mathrm{NaOH})}^{\mathrm{b}}= & \mathfrak{D}_{\mathrm{Na}^{+}, \mathrm{w}}^{0}+2.599 \times 10^{-6} \times C_{\mathrm{NaOH}}^{1 / 2}-2.114 \times 10^{-5} \\
& \times C_{\mathrm{NaOH}}+2.558 \times 10^{-5} \times C_{\mathrm{NaOH}}^{3 / 2}-1.033 \times 10^{-5} \\
& \times C_{\mathrm{NaOH}}^{2}
\end{aligned}
$$

$$
\begin{aligned}
\mathfrak{D}_{\mathrm{OH}^{-}, \mathrm{w}(\mathrm{NaOH})}^{\mathrm{b}}= & \mathfrak{D}_{\mathrm{Na}^{+}, \mathrm{w}}^{0}+3.747 \times 10^{-6} \times C_{\mathrm{NaOH}}^{1 / 2}+7.090 \times 10^{-5} \\
& \times C_{\mathrm{NaOH}}+1.708 \times 10^{-4} \times C_{\mathrm{NaOH}}^{3 / 2}+9.499 \times 10^{-5} \\
& \times C_{\mathrm{NaOH}}^{2}
\end{aligned}
$$

$\mathfrak{D}_{+,-}^{\mathrm{b}}=\frac{C^{0.5}\left(z_{+} \mathfrak{D}_{+, \mathrm{w}}-z_{-} \mathfrak{D}_{-, \mathrm{w}}\right)\left(1+q^{0.5}\right) T^{3 / 2}\left(z_{+} \nu_{+}\right)^{0.5}}{G C_{0}\left(z_{+}-z_{-}\right)^{0.5} z_{+}^{2} z_{-}^{2} q}$

$q=\frac{-z_{+} z_{-}}{z_{+}-z_{-}} \frac{l_{+}^{0}+l_{-}^{0}}{z_{+}^{0}-z_{-} l_{-}^{0}}$.

This work aims to improve the Maxwell-Stefan modeling for the chlor-alkali process and to increase its applicability to higher current densities. In contrast with the work of Van der Stegen, the ionic fixed group (membrane) concentration is defined based on the known membrane properties. As proposed by Krishna [19], both the concentration (chemical potential) gradient and the electrical potential gradient can be calculated simultaneously using an augmented matrix method. By adopting this method, no further assumption about the potential gradient is needed.

This paper also investigates the influence of the Maxwell-Stefan diffusivities on the membrane performance in 
terms of membrane permselectivity (sodium transport number), membrane potential, and relative water transport number. It compares the fitted values of diffusivities with the more general correlations which are applicable for different operating conditions such as concentration, temperature, and current density. The model is then validated with the experimental data reported in the literature for the chlor-alkali system at 2 and $3 \mathrm{kA} \mathrm{m}^{-2}$ [20-23]. Lastly, the model predicts the membrane performance in terms of membrane permselectivity and membrane potential for high current densities up to $30 \mathrm{kA} \mathrm{m}^{-2}$.

\section{Mathematical model approach}

\subsection{Maxwell-Stefan equation}

Maxwell-Stefan theory is a steady-state force balance between driving forces and friction forces acting on a certain component in the mixture. Equation (11) presents the relation between the driving force on a component $i$ in the mixture and the sum of the friction forces between $i$ and the other component $j$ in terms of mole fraction [9].

$C_{\mathrm{tot}} X_{i}\left(R T \frac{\mathrm{d} \ln a_{i}}{\mathrm{~d} x}+z_{i} F \frac{\mathrm{d} \varphi}{\mathrm{d} x}\right)=\sum_{j \neq i}^{n} \frac{R T}{\mathfrak{D}_{i, j}}\left(X_{i} N_{j}-X_{j} N_{i}\right)$.

The derivation of the driving forces of the generalized Maxwell-Stefan is based on irreversible thermodynamics $[9,24]$. If the system contains ions, the partial molar Gibbs free energy depends not only on the chemical potential $\left(\mu_{\mathrm{i}}\right)$, but also on the electrical potential $(\phi)$. The combination of these potentials is called the electrochemical potential $\left(\eta_{\mathrm{i}}\right)$ as given in Eq. (12) [25].

$\mathrm{d} \eta_{\mathrm{i}}=\mathrm{d} \mu_{\mathrm{i}}+z_{\mathrm{i}} F \mathrm{~d} \varphi=\bar{V}_{\mathrm{i}} \mathrm{d} P+R T \mathrm{~d} \ln a_{\mathrm{i}}+z_{\mathrm{i}} F \mathrm{~d} \varphi$,

where $\mathcal{F}$ is the Faraday constant, $\bar{V}_{\mathrm{i}}$ is the partial molar volume of the solvent, $P$ is the pressure, $R$ is the universal gas constant, $T$ is the temperature, and $z_{i}$ is ionic charge of component $i$. The activity of component $i\left(a_{\mathrm{i}}\right)$ is defined by Eq. (13) using the activity coefficient $\gamma_{i}$ to account for the non-ideal solution.

$a_{\mathrm{i}}=\gamma_{\mathrm{i}} \frac{C_{\mathrm{i}}}{C_{\mathrm{i}}^{0}}$.

The contribution of the pressure gradient is negligible in electrochemical cells when compared to the concentration and the electrical potential gradients [2, 9, 26]. For an ideal system, the generalized Maxwell-Stefan equation from Eq. (11) can be written in terms of the concentration (Eq. 14). The relation between the ionic fluxes and the current density is shown in Eq. (15). Hence, the electroneutrality condition needs to be met according to Eq. (16). $\frac{\mathrm{d} C_{i}}{\mathrm{~d} x}+\frac{z_{i} C_{i} F}{R T} \frac{\mathrm{d} \varphi}{\mathrm{d} x}=\sum_{j \neq i}^{n} \frac{1}{C_{\mathrm{tot}} \mathfrak{D}_{i, j}}\left(C_{i} N_{j}-C_{j} N_{i}\right)$

$I=F \sum_{i=1}^{n} z_{i} N_{i}$

$\sum_{i=1}^{n} z_{i} C_{i}+z_{\mathrm{m}} C_{\mathrm{m}}=0$

\subsection{Input parameters and boundary conditions}

\subsubsection{Input parameters}

The input parameters used in the model are presented in Table 2. The generalized Maxwell-Stefan equation in Eq. (14) is derived for an ideal solution with constant pressure and temperature. The concentration of the stationary fixed charges per void fraction in the membrane is calculated by Eq. $(17)[8,11,27]$. The EW is defined as the dry weight of polymer in gram per mole of sulfonic acid groups. The ratio of weight fraction of fixed ionic groups and electrolyte in the ion cluster $\left(f_{\mathrm{m}} / f_{\mathrm{e}}\right)$ is around $0.4-1.32$ depending on the membrane properties and electrolyte concentration [11]. The density of the sodium hydroxide solution in equilibrium with the membrane is used to represent the density of the electrolyte adsorbed in the membrane $\left(\rho_{\mathrm{e}}\right)$.

$C_{\mathrm{m}}=\frac{1000 \times \rho_{\mathrm{e}}}{\mathrm{EW} \times W_{\mathrm{w}}}\left(\frac{f_{\mathrm{m}}}{f_{\mathrm{e}}}\right)$.

The water uptake $\left(W_{\mathrm{w}}\right)$ in the membrane depends on the EW and it is a function of the sodium hydroxide concentration. The water content decreases with increasing EW. The correlations for the water uptake in weight percentage of dry polymer as a function of sodium hydroxide up to $10 \mathrm{M}$ are given in Eqs. $(18,19)$, for sulfonate EW1100 and sulfonate EW1200 [11].

$$
\begin{aligned}
W_{\mathrm{w}, \text { sulfonate } \mathrm{EW}=1100}= & -0.0052 \times\left(0.001 C_{\mathrm{NaOH}}\right)^{3}+0.1655 \\
& \times\left(0.001 C_{\mathrm{NaOH}}\right)^{2}-2.7085 \\
& \times\left(0.001 C_{\mathrm{NaOH}}\right)+36.682
\end{aligned}
$$

$$
\begin{aligned}
W_{\mathrm{w}, \text { sulfonate } \mathrm{EW}=1200}= & -0.0022 \times\left(0.001 C_{\mathrm{NaOH}}\right)^{3}+0.1212 \\
& \times\left(0.001 C_{\mathrm{NaOH}}\right)^{2}-1.975 \\
& \times\left(0.001 C_{\mathrm{NaOH}}\right)+27.165
\end{aligned}
$$

The concentration of water in the anolyte and the catholyte is calculated based on the density correlations and 
Table 2 Input parameters used in the model

\begin{tabular}{|c|c|c|}
\hline Input parameter & Value & References \\
\hline Temperature $\left({ }^{\circ} \mathrm{C}\right)$ & $25-90$ & \\
\hline Current density $\left(\mathrm{kA} \mathrm{m}^{-2}\right)$ & $2-30$ & \\
\hline Sodium hydroxide (wt\%) as catholyte & $10-35$ & \\
\hline Sodium chloride (wt\%) as anolyte & 18 and 25 & \\
\hline Wet membrane thickness (mm) & 0.1 and 0.27 & \\
\hline $\mathrm{EW}\left(\mathrm{g} \mathrm{mol}^{-1}\right)$ & 1100,1150 and 1200 & \\
\hline Void fraction $\left(\mathrm{m}^{3}{ }_{\text {void }} \mathrm{m}^{-3}{ }_{\mathrm{m}}\right)$ & 0.27 & {$[8]$} \\
\hline Membrane water content (wt $\%$ dry polymer) & Equations $(18,19)$ & \\
\hline Fixed ionic groups concentration $\left(\mathrm{mol} \mathrm{m}^{-3}{ }_{\text {void }}\right)$ & Equation (17) & \\
\hline$f_{\mathrm{m}} / f_{\mathrm{e}}(-)$ & 1 & \\
\hline $\mathrm{pKw}$ & 12.60 at $80\left({ }^{\circ} \mathrm{C}\right)$ & {$[28]$} \\
\hline
\end{tabular}

weight fraction of $\mathrm{NaCl}$ and $\mathrm{NaOH}$ as a function of the temperature as given in Eqs. (20-30) [11].

$$
\begin{aligned}
C_{\mathrm{w}, \text { anolyte }} & =10^{3} \times\left(1-W_{\mathrm{NaCl}} / 100\right) \times \rho_{\mathrm{NaCl}} / M_{\mathrm{w}} \\
\rho_{\mathrm{NaCl}}= & Q_{\mathrm{NaCl}}+R_{\mathrm{NaCl}} \times W_{\mathrm{NaCl}}+S_{\mathrm{NaCl}} \times W_{\mathrm{NaCl}}^{2} \\
Q_{\mathrm{NaCl}}= & 1.0004075-0.71687895 \times 10^{-5} \\
& \times T_{\mathrm{c}}-0.51792075 \times 10^{-5} \times T_{\mathrm{c}}^{2} \\
& +0.1054032 \times 10^{-7} \times T_{\mathrm{c}}^{3}
\end{aligned}
$$$$
R_{\mathrm{NaCl}}=0.0074569085-0.2960572 \times 10^{-4}
$$$$
\times T_{\mathrm{c}}+0.30564225 \times 10^{-6}
$$$$
\times T_{\mathrm{c}}^{2}-0.934493315 \times 10^{-9} \times T_{\mathrm{c}}^{3}
$$

$$
\begin{aligned}
S_{\mathrm{NaCl}}= & 0.18372605 \times 10^{-4}+0.42360185 \times 10^{-6} \\
& \times T_{\mathrm{c}}-0.51483125 \times 10^{-8} \times T_{\mathrm{c}}^{2} \\
& +0.1794537 \times 10^{-10} \times T_{\mathrm{c}}^{3}
\end{aligned}
$$

$C_{\mathrm{w}, \text { catholyte }}=10^{3} \times\left(1-W_{\mathrm{NaOH}} / 100\right) \times \rho_{\mathrm{NaOH}} / M_{\mathrm{w}}$

$$
\begin{aligned}
\rho_{\mathrm{NaOH}}= & Q_{\mathrm{NaOH}}+R_{\mathrm{NaOH}} \times W_{\mathrm{NaOH}}+S_{\mathrm{NaOH}} \times W_{\mathrm{NaOH}}^{2} \\
& +T_{\mathrm{NaOH}} \times W_{\mathrm{NaOH}}^{3}
\end{aligned}
$$

$$
\begin{aligned}
Q_{\mathrm{NaOH}}= & 1.00224925-0.116831975 \times 10^{-3} \\
& \times T_{\mathrm{c}}-0.3210971 \times 10^{-5} \times T_{\mathrm{c}}^{2} \\
R_{\mathrm{NaOH}}= & 0.01148599-0.319841025 \times 10^{-4} \times T_{\mathrm{c}} \\
& +0.21510285 \times 10^{-6} \times T_{\mathrm{c}}^{2}
\end{aligned}
$$

$$
\begin{aligned}
S_{\mathrm{NaOH}}= & 0.19658565 \times 10^{-5}+0.761527825 \times 10^{-6} \times T_{\mathrm{c}} \\
& -0.61560685 \times 10^{-8} \times T_{\mathrm{c}}^{2}
\end{aligned}
$$

$$
\begin{aligned}
T_{\mathrm{NaOH}}= & -0.334691125 \times 10^{-6}+0.7552771 \times 10^{-8} \times T_{\mathrm{c}} \\
& +0.661632323 \times 10^{-10} \times T_{\mathrm{c}}^{2} .
\end{aligned}
$$

\subsubsection{Boundary conditions}

In this paper, we focus on the investigation of the mass transfer behavior inside the membrane. Therefore, the mass transfer resistance is only considered inside the membrane by assuming that a high mass transfer takes place in the bulk solution. The Donnan equilibrium theory is applied to define the concentration of ions at the interface (Table 3 ). The Donnan equilibrium for all ions at the membrane surfaces is expressed in Eq. (31) using the same distribution ratio $(K)$ shown in Eq. (32) [8, 27, 29]. Figure 1 depicts the concentration jump of the ionic species at the solution and the membrane interface for both anolyte and catholyte sides. The ion concentration at the solution interface is assumed to be the same as that of the bulk concentration.

$C_{i}^{\mathrm{int}, \mathrm{s}}=C_{i}^{\mathrm{m}} \frac{1}{K^{z_{i}}}$

$K=\sqrt{\frac{\sum_{i=1}^{n_{\mathrm{ion}}} C_{i, \mathrm{pos}}^{\mathrm{m}}}{\sum_{i=1}^{n_{\mathrm{ion}}} C_{i, \mathrm{neg}}^{\mathrm{m}}}}$.

The concentration of water is calculated using the density correlations given in Eqs. (20-30). The density correlation is available for the mixed electrolyte of sodium hydroxide and sodium chloride but not for the sulfonate group of the membrane. Considering the simplification of the model, the total sodium ion, calculated from the Donnan equilibrium at the left boundary, is used to define the weight percentage 
Table 3 Boundary conditions at the anolyte-membrane interface $(z=0)$ and at the catholytemembrane interface $(z=1)$

$$
\begin{array}{ll}
\hline z=0 & z=1 \\
\hline C_{\mathrm{Na}^{+}, 1}^{\mathrm{int}, A}=C_{\mathrm{Na}^{+}, 1}^{\mathrm{bulk}, A}=\frac{C_{\mathrm{Na}^{+}, 1}^{\mathrm{m}}}{K_{\mathrm{l}}} & C_{\mathrm{Na}^{+}, \mathrm{r}}^{\mathrm{int}, C}=C_{\mathrm{Na}^{+}, \mathrm{r}}^{\mathrm{bull}, C}=\frac{C_{\mathrm{Na}^{+}, \mathrm{r}}^{\mathrm{m}}}{K_{\mathrm{r}}} \\
C_{\mathrm{OH}^{-}, 1}^{\mathrm{int}, A}=C_{\mathrm{OH}^{-}, 1}^{\mathrm{bulk}, A}=C_{\mathrm{OH}^{-}, 1}^{\mathrm{m}} \times K_{\mathrm{l}} & C_{\mathrm{OH}^{-}, \mathrm{r}}^{\mathrm{int}, A}=C_{\mathrm{OH}^{-}, \mathrm{r}}^{\mathrm{m}}=C_{\mathrm{OH}^{-}, \mathrm{r}}^{\mathrm{m}} \times K_{\mathrm{r}} \\
C_{\mathrm{Cl}^{-}, 1}^{\mathrm{int}, A}=C_{\mathrm{Cl}^{-}, 1}^{\mathrm{m}}=-\frac{1}{z_{\mathrm{Cl}^{-}}}\left(\int_{i, i \neq \mathrm{Cl}^{-}}^{n} z_{i} C_{i, 1}^{\mathrm{m}}\right) & C_{\mathrm{Cl}^{-}, \mathrm{r}}^{\mathrm{int} C}=C_{\mathrm{Cl}^{-}, \mathrm{r}}^{\mathrm{bulk}, C}=-\frac{1}{z_{\mathrm{Cl}^{-}}}\left(\int_{i, i \neq \mathrm{Cl}^{-}}^{n} z_{i} C_{i, \mathrm{r}}^{\mathrm{m}}\right) \\
C_{\mathrm{H}_{2} \mathrm{O}, 1}^{\mathrm{m}}=\mathrm{NaCl} \text { density correlation (Eqs. 20, 33) } & C_{\mathrm{H}_{2} \mathrm{O}, \mathrm{r}}^{\mathrm{m}}=\mathrm{NaOH} \text { density correlation (Eqs. 25, 34) } \\
\hline
\end{array}
$$

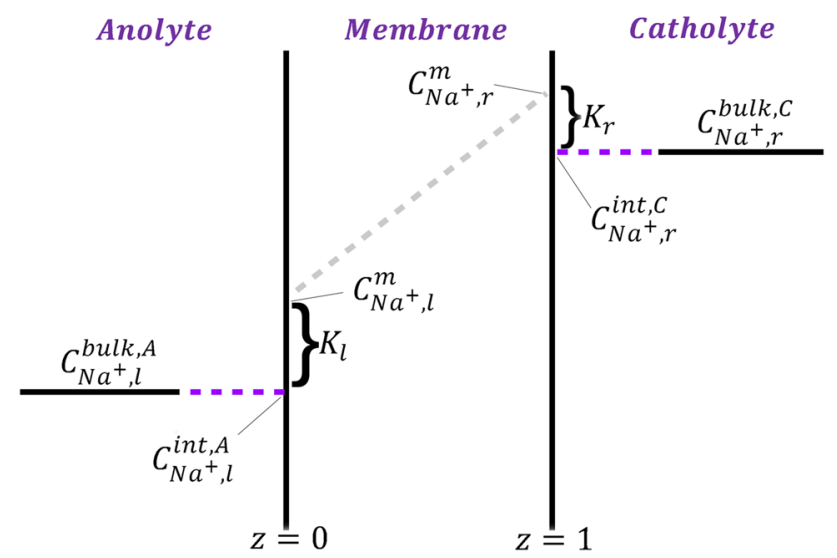

Fig. 1 Schematic drawing of the concentration jump of sodium ion between the solution and the membrane interface using the Donnan equilibrium potential. The sodium concentration at the solution interface is assumed to be equal to the bulk concentration

of sodium chloride as presented in Eq. (33). Similarly, the total sodium ion at the right boundary determines the weight percentage of sodium hydroxide shown in Eq. (34).

$$
\begin{aligned}
W_{\mathrm{NaCl}, 1}= & \left(-1.094 \times 10^{-6} \times T_{\mathrm{c}}^{2}-1.22 \times 10^{-4} \times T_{\mathrm{c}}-0.01488\right) \\
& \times\left(C_{\mathrm{Na}^{+}, 1}^{\mathrm{m}} \times 10^{-3}\right)^{2}+\left(1.375 \times 10^{-5} \times T_{\mathrm{c}}^{2}\right. \\
& \left.+1.844 \times 10^{-3} \times T_{\mathrm{c}}+5.652\right) \times C_{\mathrm{Na}^{+}, 1}^{\mathrm{m}} \times 10^{-3} \\
W_{\mathrm{NaOH}, \mathrm{r}}= & \left(-3.656 \times 10^{-7} \times T_{\mathrm{c}}^{2}-4.351 \times 10^{-5} \times T_{\mathrm{c}}-6.097 \times 10^{-2}\right) \\
& \times\left(C_{\mathrm{Na}^{+}, \mathrm{r}}^{\mathrm{m}} \times 10^{-3}\right)^{2}+\left(7.937 \times 10^{-6} \times T_{\mathrm{c}}^{2}+1.083 \times 10^{-3} \times T_{\mathrm{c}}+3.631\right) \\
& \times C_{\mathrm{Na}^{+}, \mathrm{r}}^{\mathrm{m}} \times 10^{-3} .
\end{aligned}
$$

\subsection{Augmented matrix}

The Maxwell-Stefan equation given in Eq. (14) forms a system of non-linear differential algebraic equations (DAEs). The built-in pdepe solver in Matlab® can solve DAEs using the ordinary differential equations (ODE15s) solver, only applicable for DAE index 1 or index 0. The index of DAEs is defined from the number of differentiations needed to reduce DAEs to ODEs. Equation (14) consists of both concentration and potential gradients (DAE index 2), which cannot be solved by the built-in pdepe solver in Matlab. The DAE index 2 is reduced to index 1 by applying the augmented matrix method as proposed by Krishna et al. [19] shown in Eq. (35).

$b_{i} \equiv \frac{\mathrm{d} C_{i}}{\mathrm{~d} x}=\sum_{j \neq i}^{n} \frac{1}{C_{\mathrm{tot}} \mathfrak{P}_{i, j}}\left(C_{i} N_{j}-C_{j} N_{i}\right)-\frac{C_{i} z_{i} F}{R T} \frac{\mathrm{d} \varphi}{\mathrm{d} x}$.

The non-linear flux equations need to be arranged in a matrix format (Eqs. 36-40). The derivation of augmented formulation is explained in Appendix. The concentration gradient $\left(\mathrm{d} C_{i} / \mathrm{d} z\right)$ as driving force in $\left(b_{i}\right)$ is a linear combination of both flux $\left(N_{i}\right)$ and the potential gradient $(\mathrm{d} \varphi / \mathrm{d} z)$.

$(J)=-[B]^{-1}(b)$

$\left(\begin{array}{c}J_{i} \\ J_{i+1} \\ \cdots \\ J_{n-1} \\ J_{n}\end{array}\right)=\left(\begin{array}{c}N_{i} \\ N_{i+1} \\ \cdots \\ N_{n-1} \\ \frac{\mathrm{d} \varphi}{\mathrm{d} x}\end{array}\right)$

$[B]=\left[\begin{array}{cc}\delta_{\mathrm{m}}[A] & C_{i} z_{i} \frac{F}{R T} \\ z_{i} & 0\end{array}\right]$

$[A]=A_{i, j}=\frac{C_{i}}{C_{\text {tot }} \mathfrak{D}_{i, j}} ; \quad i \neq j=1,2, \ldots, n-1$ and

$A_{i, i}=-\sum_{\substack{k=1 \\ i \neq k}}^{n} \frac{C_{k}}{C_{\mathrm{tot}} \mathfrak{D}_{i, k}} ; \quad i=1,2, \ldots, n-1$

$\left(\begin{array}{c}b_{i} \\ b_{i+1} \\ \cdots \\ b_{n-1} \\ b_{n}\end{array}\right)=\left(\begin{array}{c}\frac{\mathrm{d} C_{1}}{\mathrm{~d} z_{2}} \\ \frac{\mathrm{d} C_{2}}{\mathrm{~d} z} \\ \cdots \\ \frac{\mathrm{d} C_{n-1}}{\mathrm{~d} z} \\ \frac{I}{\mathcal{F}}\end{array}\right)$ 


\subsection{Model summary}

The ion concentration profiles are calculated with the built-in pdepe solver in Matlab by solving the flux equations (Eq. 35) based on the continuity equation shown in Eq. (41), except for the chloride ion concentration which follows from the electroneutrality condition. The initial sodium ion concentration is the sum of the concentration of all negative ions including the fixed charged group of the membrane. The initial concentration of water and other negative ions are arbitrary and are not of influence on the steady-state solution. We use the default setting of Matlab of $1 \times 10^{-3}$ and $1 \times 10^{-6}$ for the relative and the absolute error tolerance, respectively. The fluxes are constant at steady-state condition. From the fluxes, the membrane permselectivity in terms of sodium transport number for each given current density can be calculated using Eq. (42). The relative water transport number is the ratio of the flux of water and flux of sodium ions (Eq. 43). The $\mathrm{pH}$ inside the membrane can also be estimated from the hydroxide concentration as given in Eq. (44).

$\delta_{\mathrm{m}} \frac{\partial C_{i}}{\partial t}=\frac{\partial N_{i}}{\partial z}$

$t_{i}=\frac{z_{i} F N_{i}}{I} ; \quad \sum_{i=1}^{n_{\text {ions }}} t_{i}=1$

$T_{\mathrm{H}_{2} \mathrm{O}}=N_{\mathrm{H}_{2} \mathrm{O}} / N_{\mathrm{Na}^{+}}$

$\mathrm{pH}=\mathrm{pK}_{\mathrm{w}}-\mathrm{pOH}$.

\subsection{Maxwell-Stefan diffusivities}

Table 4 presents the correlations for Maxwell-Stefan diffusivities used in this model. The Chapman correlation for bulk diffusivities for concentrated solution is substituted in Eq. (1) from Wesselingh et al. to estimate the diffusivities in the membrane. Water self-diffusivity as a function of the temperature is given in Eq. (45) [30]:

$\mathfrak{D}_{\mathrm{w}}=\mathfrak{D}_{\mathrm{w}}^{0}\left(T / T_{\mathrm{S}}-1\right)^{\gamma} ; \quad \mathfrak{D}_{\mathrm{w}}^{0}=1.635 \times 10^{-8} \mathrm{~m}^{2} \mathrm{~s}^{-1} ;$

$T_{\mathrm{s}}=215.05 \mathrm{~K} ; \quad \gamma=2.063$.

We apply Eq. (3) not only for the positive ion-fixed charge groups $\left(\mathfrak{D}_{\mathrm{Na}^{+}, \mathrm{SO}_{3}^{-}}^{\mathrm{m}}\right)$ but also for the negative ion-fixed charge groups $\left(\mathfrak{D}_{\mathrm{OH}^{-}, \mathrm{SO}_{3}^{-}}^{\mathrm{m}}, \mathfrak{D}_{\mathrm{Cl}^{-}, \mathrm{SO}_{3}^{-}}^{\mathrm{m}}\right)$ and the negative ion-positive ion interactions inside the membrane $\left(\mathfrak{D}_{\mathrm{Na}^{+}, \mathrm{Cl}^{-}}^{\mathrm{m}}, \mathfrak{D}_{\mathrm{Na}^{+}, \mathrm{OH}^{-}}^{\mathrm{m}}\right.$ ). For the bulk concentration $\left(C_{0}\right)$ inside the membrane in Eq. (9), the fixed charge groups are included. The value of $G=1000 \mathrm{~K}^{3 / 2} \mathrm{M}^{-1 / 2}$ is used for sodium chloride and the average value of $G=2000 \mathrm{~K}^{3 / 2} \mathrm{M}^{-1 / 2}$ is given for sodium hydroxide throughout the simulation. No correlation is available for the diffusion coefficient of negative ion-negative ion $\left(\mathfrak{D}_{\mathrm{OH}^{-}, \mathrm{Cl}^{-}}\right)$and a base case value of $1.0 \times 10^{-10} \mathrm{~m}^{2} \mathrm{~s}^{-1}$ is used in this model. The calculated values for three different temperatures are listed in Table 5. Table 5 contains four sets of Maxwell-Stefan diffusivities used in the model simulation. It should be noted that the fitted values of diffusivities obtained by Visser et al. were used at $25^{\circ} \mathrm{C}$ and a sodium concentration up to $4 \mathrm{M}$. Therefore, this set of diffusivities is less applicable for the chloralkali system. However, due to very limited availability of data for Maxwell-Stefan diffusivities, these values are used in the simulation for comparison.

\section{Results and discussion}

\subsection{Concentration, potential gradient, and pH profiles}

Figure 2 depicts the concentration profiles of sodium, hydroxide, chloride, and water inside the membrane at $2 \mathrm{kA}$ $\mathrm{m}^{-2}$ using different values of Maxwell-Stefan diffusivities as listed in Table 5. The conditions are $80^{\circ} \mathrm{C}, \mathrm{EW}=1150$, membrane thickness $=0.25 \mathrm{~mm}, 25 \mathrm{wt} \% \mathrm{NaCl}$ as anolyte, and $32 \mathrm{wt} \% \mathrm{NaOH}$ as catholyte similar to the experimental work by Yeager [20, 21]. All sets of Maxwell-Stefan diffusivities generate non-linear concentration profiles for each component. The concentration profiles of the ions using diffusivities from Visser, Van der Stegen, and this work show similar trends, but clearly differ from the base case. The water concentration profile is similar for the diffusivities from Visser and this work, but is clearly different for the base case and van der Stegen. The profiles of the potential gradient in Fig. 3a also show a non-linear behavior and are depending on the values of diffusivities. This confirms the

Table 4 Correlations for Maxwell-Stefan diffusivities used in this model

\begin{tabular}{|c|c|}
\hline Component pair & Correlations \\
\hline $\mathfrak{D}_{\mathrm{Na}^{+}, \mathrm{w}}^{\mathrm{m}}$ & $\begin{array}{l}\mathfrak{D}_{\mathrm{Na}^{+}, \mathrm{w}}^{\mathrm{b}} \varepsilon_{\text {void }}^{1.5} \text { using } \\
\mathrm{NaCl}\end{array}$ \\
\hline $\mathfrak{D}_{\mathrm{Cl}^{-}, \mathrm{w}}^{\mathrm{m}}$ & $\mathfrak{D}_{\mathrm{Cl}^{-}, \mathrm{w}}^{\mathrm{b}} \varepsilon_{\mathrm{void}}^{1.5}$ \\
\hline $\mathfrak{D}_{\mathrm{OH}^{-}, \mathrm{w}}^{\mathrm{m}}$ & $\mathfrak{D}_{\mathrm{OH}^{-}, \mathrm{w}}^{\mathrm{b}} \varepsilon_{\text {void }}^{1.5}$ \\
\hline $\mathfrak{D}_{\mathrm{SO}_{3}^{-}, \mathrm{w}}^{\mathrm{m}}$ & $\mathfrak{D}_{\mathrm{w}} \varepsilon_{\text {void }}^{1.5}$ \\
\hline $\mathfrak{D}_{\mathrm{Na}^{+}, \mathrm{SO}_{3}^{-}}^{\mathrm{m}}$ & $0.1 \mathfrak{D}_{\mathrm{Na}^{+}, \mathrm{w}}^{\mathrm{m}}$ \\
\hline $\mathfrak{D}_{\mathrm{Cl}^{-}, \mathrm{SO}_{3}^{-}}^{\mathrm{m}}$ & $0.1 \mathfrak{P}_{\mathrm{Cl}^{-}, \mathrm{w}}^{\mathrm{m}}$ \\
\hline $\mathfrak{D}_{\mathrm{OH}^{-}, \mathrm{SO}_{3}^{-}}^{\mathrm{m}}$ & $0.1 \mathfrak{D}_{\mathrm{OH}^{-}, \mathrm{w}}^{\mathrm{m}}$ \\
\hline $\mathfrak{D}_{\mathrm{Na}^{+}, \mathrm{Cl}^{-}}^{\mathrm{m}}$ & $0.1 \mathfrak{D}_{+,-}^{\mathrm{b}}$ using $\mathrm{NaCl}$ \\
\hline $\mathfrak{D}_{\mathrm{Na}^{+}, \mathrm{OH}^{-}}^{\mathrm{m}}$ & $0.1 \mathfrak{D}_{+,-}^{\mathrm{b}}$ using $\mathrm{NaOH}$ \\
\hline $\mathfrak{D}_{\mathrm{OH}^{-}, \mathrm{Cl}^{-}}^{\mathrm{m}}$ & $1.0 \times 10^{-10} \mathrm{~m}^{2} \mathrm{~s}^{-1 \mathrm{a}}$ \\
\hline
\end{tabular}

${ }^{a}$ Base case value 
Table 5 Four sets of MaxwellStefan diffusivities in $10^{-10} \mathrm{~m}^{2}$ $\mathrm{s}^{-1}$ used in the model for the anolyte concentration $(\mathrm{NaCl})$ of $5 \mathrm{M}$ and the catholyte concentration $(\mathrm{NaOH})$ of $10 \mathrm{M}$

\begin{tabular}{|c|c|c|c|c|c|c|}
\hline \multirow[t]{2}{*}{ Component pair } & \multirow[t]{2}{*}{$\begin{array}{l}\text { Van der Stegen [2] } \\
\text { Chlor-alkali elec- } \\
\text { trolysis at } 4 \mathrm{kA} \mathrm{m}^{-2} \\
\text { Nafion (sulfonate } \\
\text { part); EW }=1015 \\
(-) \\
\text { Model fitted } \\
T=90^{\circ} \mathrm{C}\end{array}$} & \multirow[t]{2}{*}{$\begin{array}{l}\text { Visser [3] } \\
\text { Electrodialysis } \\
\text { up to } 1 \mathrm{kA} \mathrm{m}^{-2} \\
\text { Nafion } 450 ; \\
\mathrm{EW}=1100(-) \\
\text { Model fitted } \\
T=25^{\circ} \mathrm{C}\end{array}$} & \multicolumn{3}{|c|}{$\begin{array}{l}\text { This work } \\
\text { Chlor-alkali electrolysis up to } \\
30 \mathrm{kA} \mathrm{m}^{-2} \\
\text { Nafion } 1110 ; \mathrm{EW}=1100(-) \\
\varepsilon_{\text {void }}=0.27(-) \\
\text { Correlation for concentrated solu- } \\
\text { tion (Table } 4 \text { ) }\end{array}$} & \multirow[t]{2}{*}{ Basecase } \\
\hline & & & $T=25^{\circ} \mathrm{C}$ & $T=80^{\circ} \mathrm{C}$ & $T=90^{\circ} \mathrm{C}$ & \\
\hline $\mathfrak{D}_{\mathrm{Na}^{+}, \mathrm{w}}^{\mathrm{m}}$ & 11 & 5.14 & 1.88 & 5.40 & 6.13 & 1.0 \\
\hline $\mathfrak{D}_{\mathrm{Cl}^{-}, \mathrm{w}}^{\mathrm{m}}$ & $100^{\mathrm{b}}$ & $6.23^{\mathrm{a}}$ & 2.88 & 7.85 & 8.86 & 1.0 \\
\hline $\mathfrak{D}_{\mathrm{OH}^{-}, \mathrm{w}}^{\mathrm{m}}$ & 10 & $16.2^{\mathrm{a}}$ & 7.53 & 17.0 & 19.03 & 1.0 \\
\hline $\mathfrak{D}_{\mathrm{SO}_{3}^{-}, \mathrm{w}}^{\mathrm{m}}$ & 10 & 7.92 & 3.23 & 9.20 & 10.63 & 1.0 \\
\hline $\mathfrak{D}_{\mathrm{Na}^{+}, \mathrm{SO}_{3}^{-}}^{\mathrm{m}}$ & 3 & 2.26 & 0.19 & 0.54 & 0.61 & 1.0 \\
\hline $\mathfrak{D}_{\mathrm{Cl}^{-}, \mathrm{SO}_{3}^{-}}^{\mathrm{m}}$ & 0.1 & 0.169 & 0.29 & 0.79 & 0.89 & 1.0 \\
\hline $\mathfrak{D}_{\mathrm{OH}^{-}, \mathrm{SO}_{3}^{-}}^{\mathrm{m}}$ & $100^{\mathrm{b}}$ & 1.58 & 0.75 & 1.70 & 1.90 & 1.0 \\
\hline $\mathfrak{D}_{\mathrm{Na}^{+}, \mathrm{Cl}^{-}}^{\mathrm{m}}$ & $100^{\mathrm{b}}$ & 0.580 & 0.27 & 0.99 & 1.17 & 1.0 \\
\hline $\mathfrak{D}_{\mathrm{Na}^{+}, \mathrm{OH}^{-}}^{\mathrm{m}}$ & 10 & 100 & 0.26 & 0.78 & 0.94 & 1.0 \\
\hline $\mathfrak{D}_{\mathrm{OH}^{-}}^{\mathrm{m}} \mathrm{Cl}^{-}$ & $100^{\mathrm{b}}$ & $1.0^{\mathrm{c}}$ & $1.0^{\mathrm{c}}$ & $1.0^{\mathrm{c}}$ & $1.0^{\mathrm{c}}$ & 1.0 \\
\hline
\end{tabular}

${ }^{\mathrm{a} C a l c u l a t e d}$ from Eq. (1)

${ }^{b}$ Effectively no friction between the components

${ }^{\mathrm{c}}$ Base case value
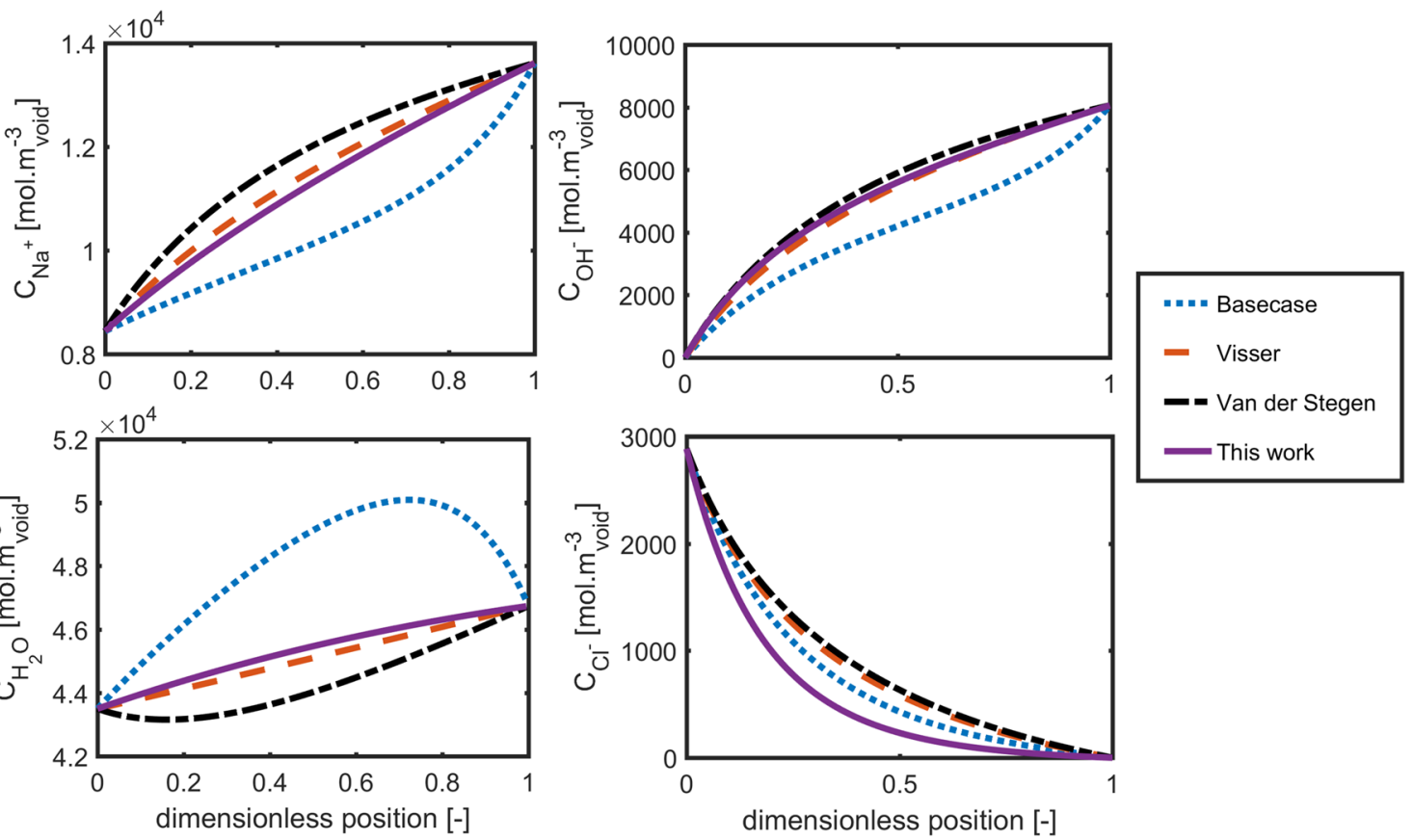

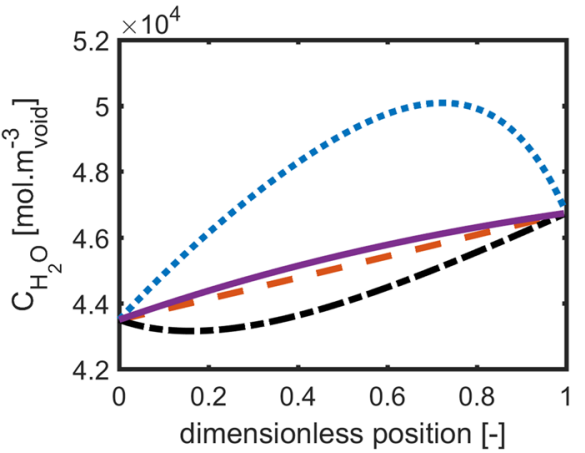

Fig. 2 Concentration profiles of sodium, hydroxide, chloride, and water as a function of position inside the membrane using different values of Maxwell-Stefan diffusivities as listed in Table 5 (see leg-

strong influence of the values of the Maxwell-Stefan diffusivities on the concentration and potential gradient profiles.

Despite the clearly different concentration profiles for the different sets of diffusivities, all models predict similar $\mathrm{pH}$ profiles inside the membrane due to the fact that $\mathrm{pH}$ is end) at $2 \mathrm{kA} \mathrm{m}^{-2} . \mathrm{EW}=1150$, membrane thickness $=0.25 \mathrm{~mm}$, temperature $=80{ }^{\circ} \mathrm{C}, 25 \mathrm{wt} \% \mathrm{NaCl}$, and $32 \mathrm{wt} \% \mathrm{NaOH}$

logarithmic (Fig. 3b). This demonstrates that the hydroxide ion concentration is relatively high, which results in a pH above 12 throughout the membrane. Similar results have been reported in the previously developed models 
$[7,31]$. It should be mentioned that in our model we use $\mathrm{pKw}=12.60$ at $80{ }^{\circ} \mathrm{C}[28]$ instead of the $\mathrm{pKw}=14$ at $25^{\circ} \mathrm{C}$.

\subsection{Model validation for low current densities}

The membrane permselectivity (sodium transport number) and the membrane potential are key performance criteria in the chlor-alkali process. To validate the models with the different diffusivity sets, the model was run with the same conditions as experiments by Yeager et al. and Berzins [20, 23 ] in which the catholyte concentration was varied from 10 to $35 \mathrm{wt} \%(\approx 2.5-12 \mathrm{M})$.

Figure $4 \mathrm{a}$ shows the sodium transport number as a function of the catholyte concentration at $2 \mathrm{kA} \mathrm{m}^{-2}$ using a monolayer sulfonate membrane with $\mathrm{EW}=1150$, membrane thickness $=0.25 \mathrm{~mm}$, and temperature $=80^{\circ} \mathrm{C}$. Similar profiles are also observed in Fig. $4 \mathrm{~b}$ for a monolayer membrane with $\mathrm{EW}=1100$ and a membrane thickness of $0.1 \mathrm{~mm}$ at $3 \mathrm{kA} \mathrm{m}^{-2}$. It is observed that the influence of the diffusivities on the calculated sodium transport number is even more pronounced than for the concentration profiles. The base case diffusivities overpredict the sodium transport number, while the opposite is observed for both the Visser and Van der Stegen cases. The diffusivities based on the empirical correlation used in our model show the best fit to the experimental work. Sensitivity analysis was performed for diffusion coefficient of negative ion-negative ion $\left(\mathfrak{D}_{\mathrm{OH}^{-}, \mathrm{Cl}^{-}}^{\mathrm{m}}\right)$ for the range $0.1 \times 10^{-10}-50 \times 10^{-10} \mathrm{~m}^{2} \mathrm{~s}^{-1}$, and no significant impact was found on the ion transport number and the membrane potential for this system. It could be because the chloride ion flux through the membrane is negligible. Therefore, a base case value of $1.0 \times 10^{-10} \mathrm{~m}^{2} \mathrm{~s}^{-1}$ is used throughout the simulation.

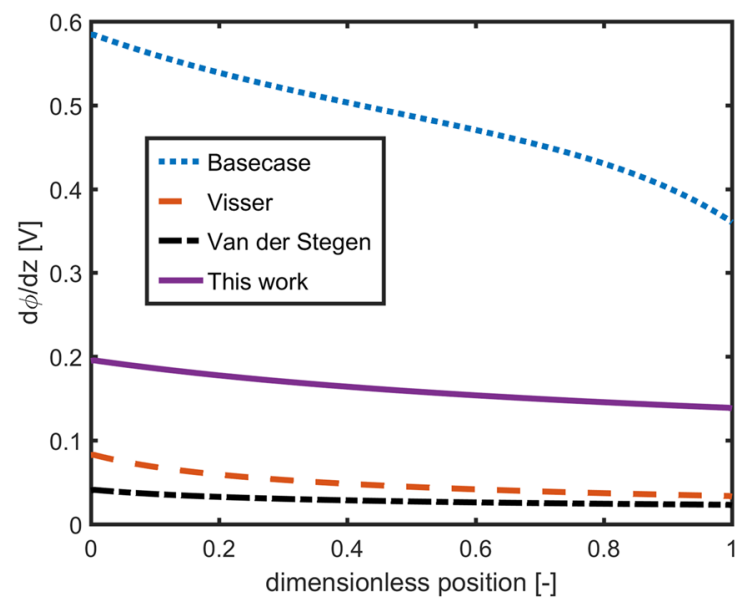

(a)

Fig. 3 Potential gradient profiles (a) and $\mathrm{pH}$ profiles (b) as a function of position in the membrane at $2 \mathrm{kA} \mathrm{m}^{-2}$ using different values of Maxwell-Stefan diffusivities as listed in Table 5 (see legend).
Water is also transported together with sodium to the catholyte site. The Maxwell-Stefan model includes the water transport via water-ion interactions. Therefore, a separate semi-empirical equation (i.e., the Schlögl equation) is no longer required. Figure 5 shows water transport calculated with the different models and compares these to experimental data. It can be seen that both Van der Stegen and Visser predict too low water transport, especially at high caustic concentrations, whereas the base case and our work show a good match. It is important to note that water concentration at the membrane interface is calculated based on the density correlations of sodium chloride and sodium hydroxide, which does not completely reflect reality since it does not take into account the density difference compared to sulfonate groups in the membrane.

The performance of the models can be explained by considering the diffusivities. Visser uses a very high binary diffusivity of sodium ion-hydroxide ion inside the membrane $\left(\mathfrak{D}_{\mathrm{Na}^{+}, \mathrm{OH}^{-}}^{\mathrm{m}}=100 \times 10^{-10} \mathrm{~m}^{2} \mathrm{~s}^{-1}\right)$, which results in a high hydroxide ion transport inside the membrane and a low sodium transport number. The diffusivity exceeds the value calculated using the correlation suggested by Chapman for $10 \mathrm{M}(\approx 32 \mathrm{wt} \%) \mathrm{NaOH}\left(\mathfrak{D}_{\mathrm{Na}^{+}, \mathrm{OH}^{-}}^{\text {bulk }}=7.5 \times 10^{-10} \mathrm{~m}^{2} \mathrm{~s}^{-1}\right.$ at $25^{\circ} \mathrm{C}$ ). The diffusivity values suggested by Van der Stegen result in even lower sodium transport numbers and negative water transport numbers. In this case, it does not seem logical that the diffusivities of chloride inside the membrane are higher than the value for infinite dilution as listed in Table 1. The diffusivities presented in this work seem more realistic and this is reflected in both sodium and relative water transport numbers.

The values of diffusivities also affect the membrane potential drop as shown in Fig. 6. The suggested values

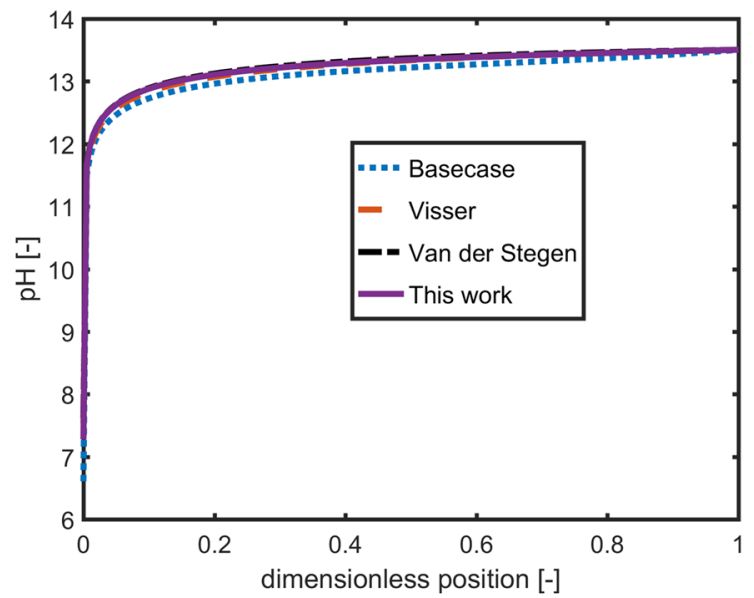

(b)

$\mathrm{EW}=1150$, membrane thickness $=0.25 \mathrm{~mm}$, temperature $=80^{\circ} \mathrm{C}$, $25 \mathrm{wt} \% \mathrm{NaCl}$, and $32 \mathrm{wt} \% \mathrm{NaOH}$ 


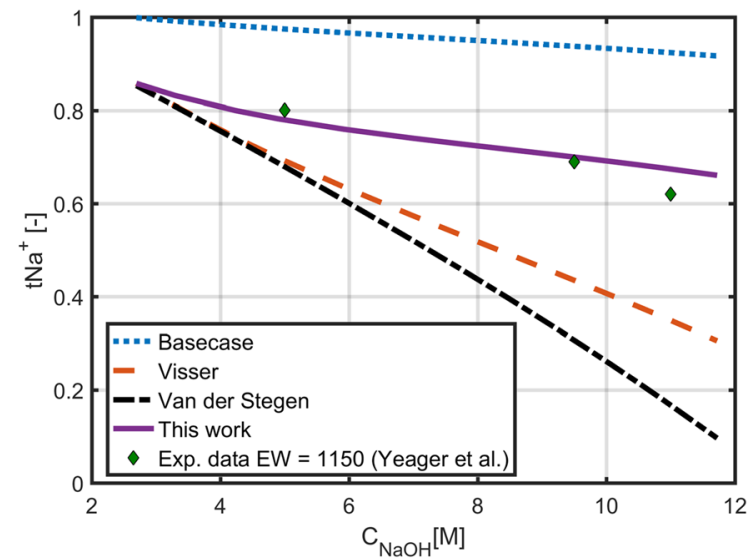

(a)

Fig. 4 Modeled and experimental data (Yeager et al. [20, 21] and Berzins [23]) of the sodium transport number as a function of catholyte concentration. For the models, the different values of Maxwell-Stefan diffusivities as listed in Table 5 are used. a Current

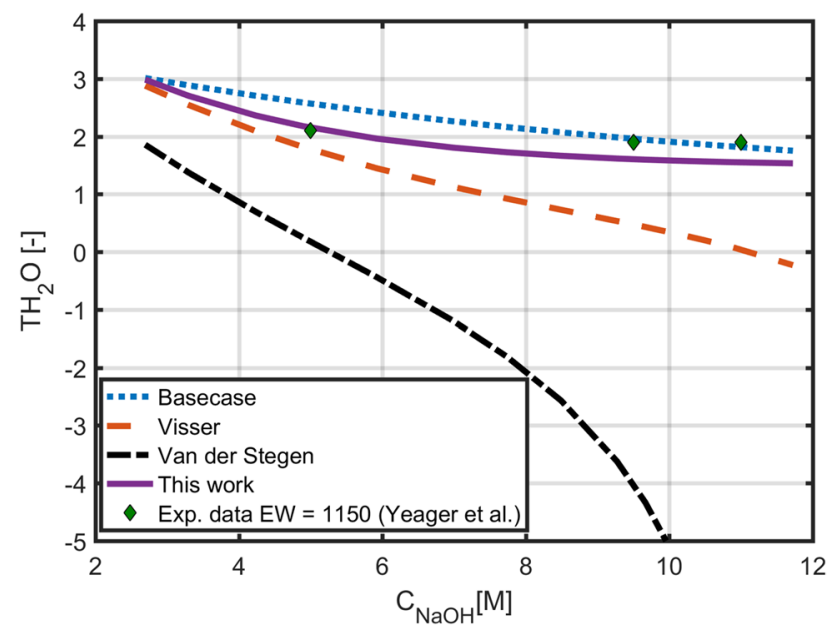

Fig. 5 Modeled and experimental data (Yeager et al. [20, 21]) of the relative water transport number as a function of catholyte concentration using different values of Maxwell-Stefan diffusivities as listed in Table 5 (see legend) at $2 \mathrm{kA} \mathrm{m}^{-2}$. $\mathrm{EW}=1150$, membrane thickness $=0.25 \mathrm{~mm}$, temperature $=80^{\circ} \mathrm{C}$ and $25 \mathrm{wt} \% \mathrm{NaCl}$

of diffusivities by Van der Stegen as a function of current density as given in Eq. (4) show an unrealistic profile. The model was run with the operating conditions reported by Bergner et al. [32] with a typical thickness of $0.29 \mathrm{~mm}$ for Nafion N954 [33] and EW =1100. Our model shows a reasonable match with the experimental values of the membrane potential at $80{ }^{\circ} \mathrm{C}$ around $0.51 \mathrm{~V}$ at $6 \mathrm{kA} \mathrm{m}^{-2}$ [34] and $0.291 \mathrm{~V}$ at $3 \mathrm{kA} \mathrm{m}^{-2}$ [11]. However, the linear correlations proposed by Bergner et al. for both their experimental data and the experimental data of Nidola [35] show higher values than the predicted model at lower current densities. The

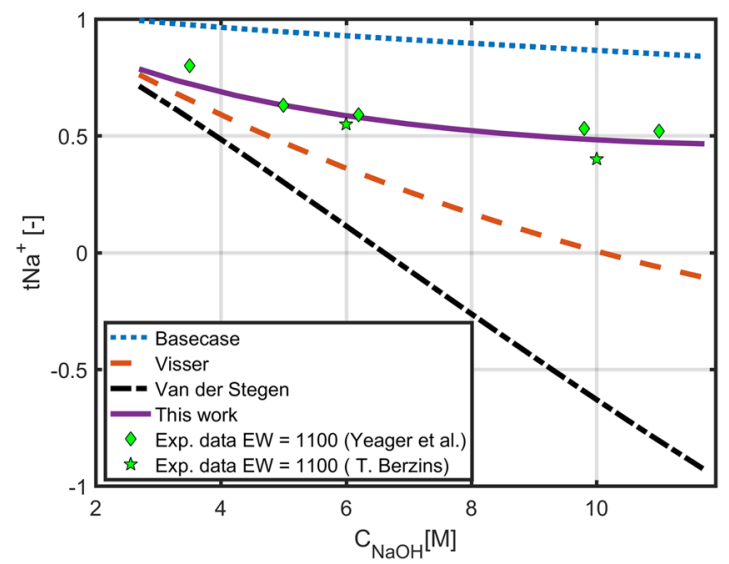

(b)

density $=2 \mathrm{kA} \mathrm{m}^{-2}, \mathrm{EW}=1150$, membrane thickness $=0.25 \mathrm{~mm}$, $25 \mathrm{wt} \% \mathrm{NaCl}$, and temperature $=80{ }^{\circ} \mathrm{C}$. b Current density $=3 \mathrm{kA}$ $\mathrm{m}^{-2}, \mathrm{EW}=1100$, membrane thickness $=0.1 \mathrm{~mm}, 25 \mathrm{wt} \% \mathrm{NaCl}$, and temperature $=80^{\circ} \mathrm{C}$

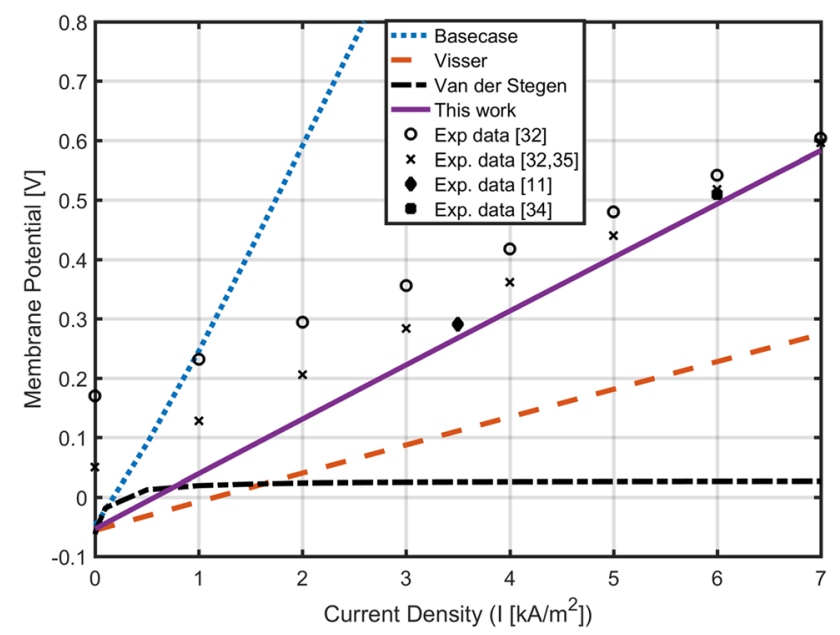

Fig. 6 Membrane potential drop as a function of current density using different values of Maxwell-Stefan diffusivities as listed in Table 5. The experimental data of Bergner et al. [32]: $\mathrm{NaCl}=18 \mathrm{wt} \%$, $\mathrm{NaOH}=33 \mathrm{wt} \%$, temperature $=90{ }^{\circ} \mathrm{C}, \mathrm{EW}=1100$, membrane thickness $=0.29 \mathrm{~mm}$ (properties of Nafion N954 [33]). The typical values of membrane potential at $80{ }^{\circ} \mathrm{C}$ for current densities of $3.5 \mathrm{kA} \mathrm{m}^{-2}$ and $6 \mathrm{kA} \mathrm{m}^{-2}$ are $0.291 \mathrm{~V}$ [11] and $0.51 \mathrm{~V}$ [34], respectively

fact that they still show a significant membrane potential at zero current density is not easy to explain. Osmotic pressure differences between the anolyte and catholyte could play a role, but it might also be related to experimental issues. They mentioned that during the membrane potential measurement, two Luggin capillaries could not be placed with sufficient accuracy (the zero gap configuration had a gap of $0.5-1 \mathrm{~mm}$ ). Chandran et al. [36] also reported similar experimental difficulties, resulting in large measured membrane potentials. 
All in all one can conclude that the model with the diffusivities presented in this work shows the best fit compared to experimental data. Prediction of the sodium transport number and water transport number is good, whereas the deviations with regard to membrane potential might also be related to issues with the experimental data. Given this good performance, we can now consider using the model to predict membrane performance at conditions for which experimental data are not yet available such as high current densities.

\subsection{Model prediction for high current densities}

The Maxwell-Stefan diffusivities suggested in this work are applied for further simulation. The model uses the operating conditions of the chlor-alkali process: $25 \mathrm{wt} \%$ $\mathrm{NaCl}$ as anolyte, $32 \mathrm{wt} \% \mathrm{NaOH}$ as catholyte, and a Nafion single-layer membrane, $\mathrm{N}-1110$ (EW $=1100$ and thickness $=0.27 \mathrm{~mm})[8,33]$. Figure 7 presents the transport number of sodium, hydroxide, water, and membrane potential drop as a function of current density from 2 to $30 \mathrm{kA}$ $\mathrm{m}^{-2}$ for low and high temperature $\left(25^{\circ} \mathrm{C}\right.$ and $\left.90{ }^{\circ} \mathrm{C}\right)$. The sodium transport number shows an increasing trend with increasing current density, which is also experimentally observed in chlor-alkali [11]. This can be explained by the fact that at low current densities, diffusion is still important compared to migration. This leads to a higher back diffusion of sodium from catholyte (around $10 \mathrm{M} \mathrm{NaOH}$ ) to anolyte (around $5 \mathrm{M} \mathrm{NaCl}$ ). At higher current densities, the contribution of diffusion diminishes compared to the increasing migration term. Increased temperature results in decreased membrane permselectivity, which can be explained by the fact that higher temperature leads to higher mobility of ions and enhances ion diffusion. The model also predicts that the chloride ion transport is negligible for both high current density and temperature.

As shown in Fig. 7, the membrane potential is significantly lower for higher temperature. This is related to the increased conductivity of the membrane. In the model, the conductivity is not explicitly present as a variable but it is taken into account in the diffusivities as shown in Eq. (2). The infinite dilution of diffusivities is related to the limiting ionic conductivity. The ionic conductivity increases with increasing temperature which results in a lower resistance, thus lower membrane potential drop.

Figure 8 illustrates the effects of the fixed ionic group concentration and the current densities on the membrane permselectivity and the membrane potential. The model predicts a higher sodium transport number with higher fixed ionic group concentration and current densities. The latter is in line with the results shown in Fig. 7. Higher sulfonate groups in the membrane prevents the transport of the hydroxide ion as co-ion based on the Donnan exclusion and enhances the sodium ion transport as counter-ion. The water concentration decreases with increasing sulfonate groups concentration, and the model predicts a lower water
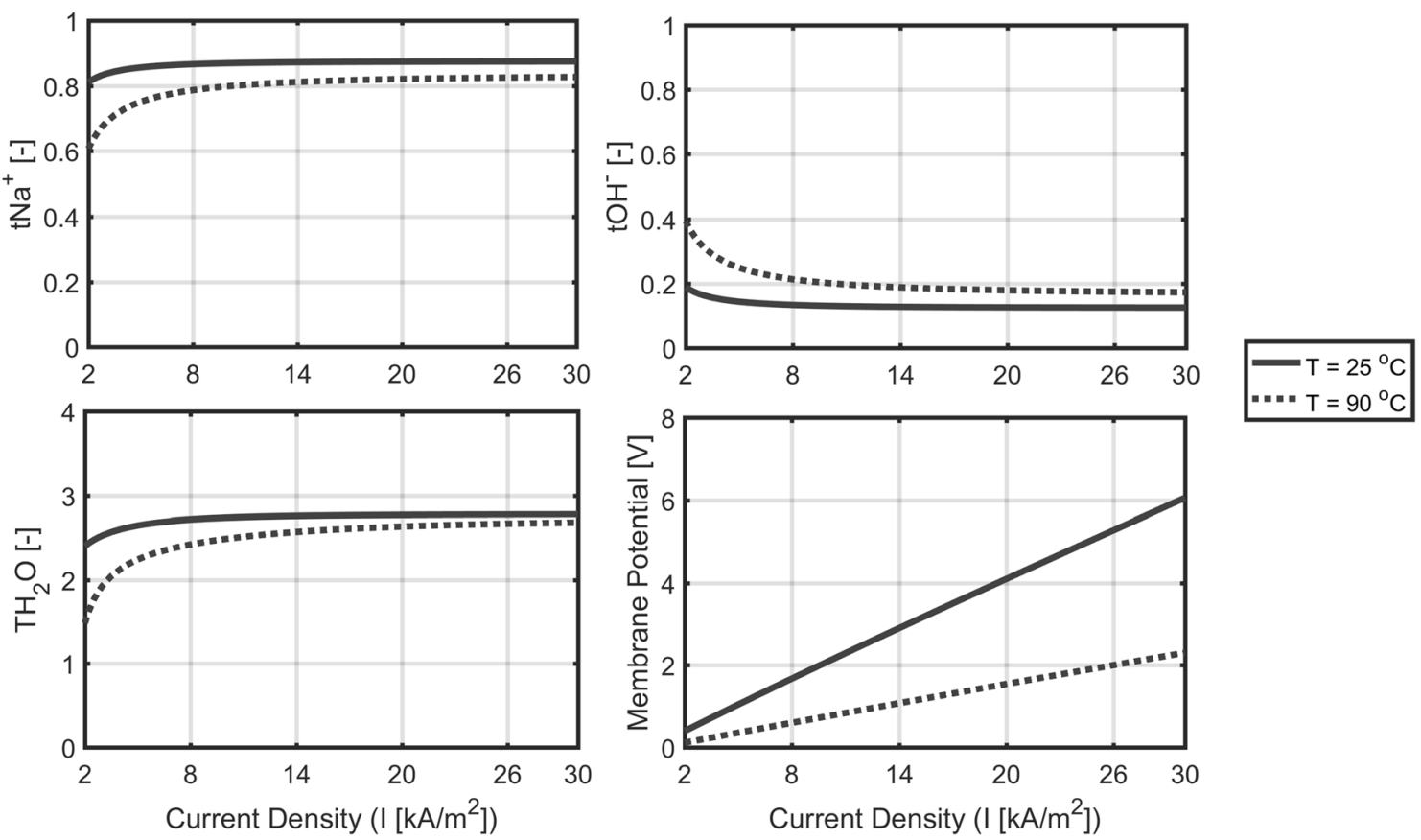

Fig. 7 The transport number of sodium, hydroxide, water, and membrane potential as a function of current density using the MaxwellStefan diffusivities based on this work for two different temperatures

(see legend). The model simulation used the Nafion 1110 with properties: $\mathrm{EW}=1100$, membrane thickness $=0.27 \mathrm{~mm}, 25 \mathrm{wt} \% \mathrm{NaCl}$ as anolyte, and $32 \mathrm{wt} \% \mathrm{NaOH}$ as catholyte 
transport for higher fixed ionic group concentration. A slight increase is observed in the membrane potential and this can be related to the decreased water concentration for higher membrane concentration.

\section{Conclusion}

A Maxwell-Stefan model has been developed to investigate the non-linear behavior of multicomponent ion and water transport inside a cation-exchange membrane. The non-linear concentration profiles, the membrane potential drop, and the transport number of ions and water strongly depend on the values of the Maxwell-Stefan diffusivities. To conclude, the combined correlations proposed by Wesselingh et al., Kraaijveld et al., and Chapman et al. show a good agreement with the available experimental data of chlor-alkali for sodium transport number and relative water transport number. Thus, it is our considered opinion that the semi-empirical correlations are suitable for defining the Maxwell-Stefan diffusivities and therefore are suitable for further simulations.

The improvement of our model compared to the previously developed models is the ability to calculate both fluxes and the membrane potential drop simultaneously by adopting the augmented matrix method. A typical expected membrane potential for chlor-alkali process around $0.5 \mathrm{~V}$ at $6 \mathrm{kA}$ $\mathrm{m}^{-2}$ and $80^{\circ} \mathrm{C}$ is well predicted by our model.
OpenAccess This article is distributed under the terms of the Creative Commons Attribution 4.0 International License (http://creativeco mmons.org/licenses/by/4.0/), which permits unrestricted use, distribution, and reproduction in any medium, provided you give appropriate credit to the original author(s) and the source, provide a link to the Creative Commons license, and indicate if changes were made.

\section{Appendix: Augmented matrix formulation}

The fixed charged groups of the cation-selective membrane are treated as a component in the aqueous electrolyte solution. The chlor-alkali process contains in total 5 components including the fixed charged groups $(n=5)$. The flux of fixed charged groups of the membrane is zero. This results in a matrix of $(n-1)$ fluxes. In addition, the concentration of the fixed charged groups is constant. The fixed charged group is therefore set as the $n$th (5th) component.

Every component is defined a number:

$\mathrm{Na}^{+}=1, \mathrm{OH}^{-}=2, \mathrm{H}_{2} \mathrm{O}=3, \mathrm{Cl}^{-}=4, \mathrm{SO}_{3}^{-}=5$.

The concentration of fixed charged group is known from the membrane property. The total concentration is the sum of the concentration of every component:

$C_{\mathrm{tot}}=\sum_{i=1}^{n} C_{i}=C_{1}+C_{2}+C_{3}+C_{4}+C_{5}$.
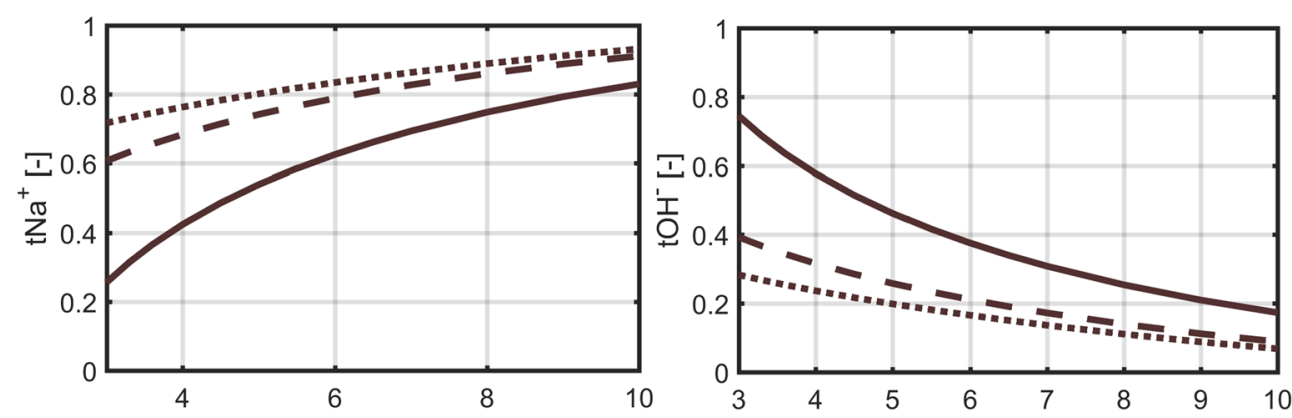
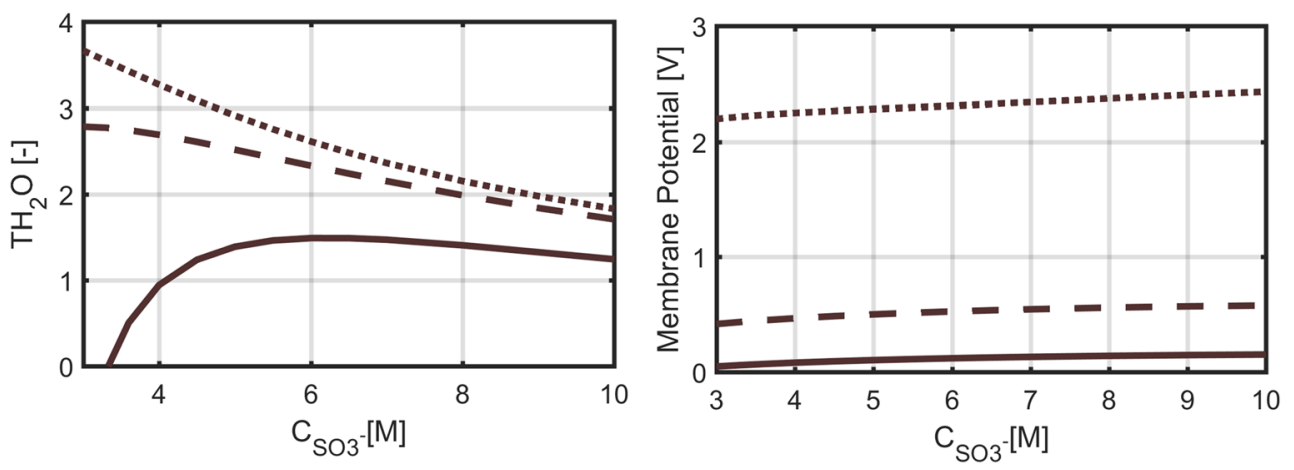

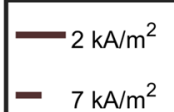

- $30 \mathrm{kA} / \mathrm{m}^{2}$
Fig. 8 The transport number of sodium, hydroxide, water, and membrane potential as a function of ionic fixed group concentration using the Maxwell-Stefan diffusivities suggested in this work for three dif- ferent current densities (see legend). Membrane thickness $=0.27 \mathrm{~mm}$, temperature $=90{ }^{\circ} \mathrm{C}, \mathrm{NaCl}$ as anolyte $=25 \mathrm{wt} \%$, and $\mathrm{NaOH}$ as catholyte $=32 \mathrm{wt} \%$ 
Based on the literature written by Krishna (1987), the DAE index 2 can be reduced to index 1 by applying the augmented matrix method [19].

$b_{i} \equiv \frac{\mathrm{d} C_{i}}{\mathrm{~d} x}=\sum_{j \neq i}^{n} \frac{1}{C_{\mathrm{tot}} \mathfrak{D}_{i, j}}\left(C_{i} N_{j}-C_{j} N_{i}\right)-\frac{C_{i} z_{i} F}{R T} \frac{\mathrm{d} \varphi}{\mathrm{d} x}$.

Except in the region close the electrode surface, where there occurs charge separation due to double-layer phenomena, the electroneutrality condition needs to be met. This means that there is no net electrical body force acting on the mixture as a whole:

$\sum_{i=1}^{n} z_{i} C_{i}=0$

Since the water does not carry either positive or negative charge $\left(z_{3}=0\right)$, one concentration variable can be eliminated:

$\sum_{i=1}^{n} z_{i} C_{i}=0=z_{1} C_{1}+z_{2} C_{2}+z_{4} C_{4}+z_{5} C_{5}$.

The concentration of the fourth component can therefore be calculated:

$C_{4}=-\left(\frac{z_{1} C_{1}+z_{2} C_{2}+z_{5} C_{5}}{z_{4}}\right)$.

Both the flux and the driving force of the fixed charge groups are zero. This leads to $(n-1)$ equations:

$$
\begin{aligned}
b_{1} \equiv \frac{\mathrm{d} C_{1}}{\mathrm{~d} x}= & -\frac{1}{C_{\mathrm{tot}}}\left(\frac{C_{2}}{\mathfrak{D}_{1,2}}+\frac{C_{3}}{\mathfrak{D}_{1,3}}+\frac{C_{4}}{\mathfrak{D}_{1,4}}+\frac{C_{5}}{\mathfrak{D}_{1,5}}\right) N_{1} \\
& +\frac{C_{1}}{C_{\mathrm{tot}} \mathfrak{D}_{1,2}} N_{2}+\frac{C_{2}}{C_{\mathrm{tot}} \mathfrak{D}_{1,3}} N_{3}+\frac{C_{4}}{C_{\mathrm{tot}} \mathfrak{D}_{1,4}} N_{4} \\
& -\frac{C_{1} z_{1} F}{R T} \frac{\mathrm{d} \varphi}{\mathrm{d} x}
\end{aligned}
$$

$b_{2} \equiv \frac{\mathrm{d} C_{2}}{\mathrm{~d} x}=\frac{C_{1}}{C_{\mathrm{tot}} \mathfrak{D}_{2,1}} N_{1}-\frac{1}{C_{\mathrm{tot}}}\left(\frac{C_{1}}{\mathfrak{D}_{2,1}}+\frac{C_{3}}{\mathfrak{D}_{2,3}}+\frac{C_{4}}{\mathfrak{D}_{2,4}}+\frac{C_{5}}{\mathfrak{D}_{2,5}}\right) N_{2}$ $+\frac{C_{3}}{C_{\mathrm{tot}} \mathfrak{D}_{2,3}} N_{3}+\frac{C_{4}}{C_{\mathrm{tot}} \mathfrak{D}_{2,4}} N_{4}-\frac{C_{2} z_{2} F}{R T} \frac{\mathrm{d} \varphi}{\mathrm{d} x}$

$$
\begin{aligned}
b_{3} \equiv \frac{\mathrm{d} C_{3}}{\mathrm{~d} x}= & \frac{C_{1}}{C_{\mathrm{tot}} \mathfrak{D}_{3,1}} N_{1}+\frac{C_{2}}{C_{\mathrm{tot}} \mathfrak{D}_{3,2}} N_{2} \\
& -\frac{1}{C_{\mathrm{tot}}}\left(\frac{C_{1}}{\mathfrak{D}_{3,1}}+\frac{C_{2}}{\mathfrak{D}_{3,2}}+\frac{C_{4}}{\mathfrak{D}_{3,4}}+\frac{C_{5}}{\mathfrak{D}_{3,5}}\right) N_{3} \\
& +\frac{C_{4}}{C_{\mathrm{tot}} \mathfrak{D}_{3,4}} N_{4}-\frac{C_{3} z_{3} F}{R T} \frac{\mathrm{d} \varphi}{\mathrm{d} x}
\end{aligned}
$$

$$
\begin{aligned}
b_{4} \equiv \frac{\mathrm{d} C_{4}}{\mathrm{~d} x}= & \frac{C_{1}}{C_{t o t} \mathfrak{D}_{4,1}} \mathrm{~N}_{1}+\frac{C_{2}}{C_{t o t} \mathfrak{D}_{4,2}} \mathrm{~N}_{2}+\frac{C_{3}}{C_{t o t} \mathfrak{D}_{4,3}} \mathrm{~N}_{3} \\
& -\frac{1}{C_{t o t}}\left(\frac{C_{1}}{\mathfrak{D}_{4,1}}+\frac{C_{2}}{\mathfrak{D}_{4,2}}+\frac{C_{3}}{\mathfrak{D}_{4,3}}+\frac{C_{5}}{\mathfrak{D}_{4,5}}\right) \mathrm{N}_{4} \\
& -\frac{C_{4} z_{4} F}{R T} \frac{\mathrm{d} \varphi}{\mathrm{d} x} .
\end{aligned}
$$

There are in total four equations with five unknowns $\left(N_{1}, N_{2}, N_{3}, N_{4}\right.$ and $\left.\mathrm{d} \varphi / \mathrm{d} x\right)$.

The current density can be defined in terms of flux:

$I=\mathcal{F} \sum_{i=1}^{n} z_{i} N_{i}$

The fixed charged groups of the cation-exchange membrane contain zero flux $\left(N_{5}=N_{\mathrm{SO}_{3}^{-}}=0\right)$ because these ions are not transported (kept in place).

$\frac{I}{\mathcal{F}}=z_{1} N_{1}+z_{2} N_{2}+z_{3} N_{2}+z_{4} N_{4}+0$.

Using the Eq. (53), there are now in total five equations with five unknowns:

$$
\begin{aligned}
b_{1} \equiv \frac{\mathrm{d} C_{1}}{\mathrm{~d} x}= & -\frac{1}{C_{\mathrm{tot}}}\left(\frac{C_{2}}{\mathfrak{D}_{1,2}}+\frac{C_{3}}{\mathfrak{D}_{1,3}}+\frac{C_{4}}{\mathfrak{D}_{1,4}}+\frac{C_{5}}{\mathfrak{D}_{1,5}}\right) N_{1} \\
& +\frac{C_{2}}{C_{\mathrm{tot}} \mathfrak{D}_{1,2}} N_{2}+\frac{C_{3}}{C_{\mathrm{tot}} \mathfrak{D}_{1,3}} N_{3}+\frac{C_{4}}{C_{\mathrm{tot}} \mathfrak{D}_{1,4}} N_{4} \\
& -\frac{C_{1} z_{1} F}{R T} \frac{\mathrm{d} \varphi}{\mathrm{d} x}
\end{aligned}
$$

$$
\begin{aligned}
b_{2} \equiv \frac{\mathrm{d} C_{2}}{\mathrm{~d} x}= & \frac{C_{1}}{C_{\mathrm{tot}} \mathfrak{D}_{2,1}} N_{1} \\
& -\frac{1}{C_{\mathrm{tot}}}\left(\frac{C_{1}}{\mathfrak{D}_{2,1}}+\frac{C_{3}}{\mathfrak{D}_{2,3}}+\frac{C_{4}}{\mathfrak{D}_{2,4}}+\frac{C_{5}}{\mathfrak{D}_{2,5}}\right) N_{2} \\
& +\frac{C_{3}}{C_{\mathrm{tot}} \mathfrak{D}_{2,3}} N_{3}+\frac{C_{4}}{C_{\mathrm{tot}} \mathfrak{D}_{2,4}} N_{4}-\frac{C_{2} z_{2} F}{R T} \frac{\mathrm{d} \varphi}{\mathrm{d} x}
\end{aligned}
$$

$$
\begin{aligned}
b_{3} \equiv \frac{\mathrm{d} C_{3}}{\mathrm{~d} x}= & \frac{C_{1}}{C_{\mathrm{tot}} \mathfrak{D}_{3,1}} N_{1}+\frac{C_{2}}{C_{\mathrm{tot}} \mathfrak{D}_{3,2}} N_{2} \\
& -\frac{1}{C_{\mathrm{tot}}}\left(\frac{C_{1}}{\mathfrak{D}_{3,1}}+\frac{C_{2}}{\mathfrak{D}_{3,2}}+\frac{C_{4}}{\mathfrak{D}_{3,4}}+\frac{C_{5}}{\mathfrak{D}_{3,5}}\right) N_{3} \\
& +\frac{C_{4}}{C_{\mathrm{tot}} \mathfrak{D}_{3,4}} N_{4}-\frac{C_{3} z_{3} F}{R T} \frac{\mathrm{d} \varphi}{\mathrm{d} x}
\end{aligned}
$$$$
b_{4} \equiv \frac{\mathrm{d} C_{4}}{\mathrm{~d} x}=\frac{C_{1}}{C_{\mathrm{tot}} \mathfrak{D}_{4,1}} N_{1}+\frac{C_{2}}{C_{\mathrm{tot}} \mathfrak{D}_{4,2}} N_{2}+\frac{C_{3}}{C_{\mathrm{tot}} \mathfrak{D}_{4,3}} N_{3}
$$$$
-\frac{1}{C_{\text {tot }}}\left(\frac{C_{1}}{\mathfrak{D}_{4,1}}+\frac{C_{2}}{\mathfrak{D}_{4,2}}+\frac{C_{3}}{\mathfrak{D}_{4,3}}+\frac{C_{5}}{\mathfrak{D}_{4,5}}\right) N_{4}
$$$$
-\frac{C_{4} z_{4} F}{R T} \frac{\mathrm{d} \varphi}{\mathrm{d} x}
$$ 
$b_{5} \equiv \frac{I}{\mathcal{F}}=z_{1} N_{1}+z_{2} N_{2}+z_{3} N_{3}+z_{4} N_{4}+0$.

This can be written in equivalent form:

$b_{i(n-1)} \equiv \frac{\mathrm{d} C_{i}}{\mathrm{~d} x}=\sum_{j=1}^{n-1} A_{i, j} N_{i}-C_{i} z_{i} \frac{F}{R T} \frac{\mathrm{d} \varphi}{\mathrm{d} x} ; \quad i=1,2, \ldots, n-1$

$A_{i, j}=\frac{C_{i}}{C_{\mathrm{tot}} \mathfrak{P}_{i, j}} ; \quad i \neq j=1,2, \ldots, n-1$

$A_{i, i}=-\sum_{\substack{k=1 \\ i \neq k}}^{n} \frac{C_{k}}{C_{\mathrm{tot}} \mathfrak{D}_{i, k}} ; \quad i=1,2, \ldots, n-1$

$b_{n} \equiv \frac{I}{\mathcal{F}}=\sum_{j=1}^{n-1} z_{i} N_{i}$

Both Eqs. 55 and 56 are defined in matrix $[A]$. The known variables in the last term of Eq. 57 can be added to matrix $[A]$ using augmented matrix $[B]$ :

$[B]=\left[\begin{array}{cc}{[A]} & C_{i} z_{i} \frac{F}{R T} \\ z_{i} & 0\end{array}\right]$

The augmented vector of the driving forces:

$\left(\begin{array}{c}b_{1} \\ b_{2} \\ \cdots \\ b_{n-1} \\ b_{n}\end{array}\right)=\left(\begin{array}{c}\frac{\mathrm{d} C_{1}}{\mathrm{~d} x} \\ \frac{\mathrm{d} C_{2}}{\mathrm{~d} x} \\ \cdots \\ \frac{\mathrm{d} C_{n-1}}{\mathrm{~d} x} \\ \frac{I}{\mathcal{F}}\end{array}\right)$.

The augmented vector of the unknown variables:

$$
\left(\begin{array}{c}
J_{1} \\
J_{2} \\
\cdots \\
J_{n-1} \\
J_{n}
\end{array}\right)=\left(\begin{array}{c}
N_{1} \\
N_{2} \\
N_{3} \\
N_{4} \\
\frac{\mathrm{d} \varphi}{\mathrm{d} x}
\end{array}\right) .
$$

The fluxes and the electro potential gradient can be therefore calculated:

$(J)=-[B]^{-1}(b)$.

The negative sign is added for the physical meaning of the fluxes to be a positive value (driving forces $(b)$ are positive, while the diagonal matrix $[B]$ contains negative values).

\section{References}

1. Best available techniques (BAT) reference document for the production of chlor-alkali. 49(97):79-81 (2014)

2. Van der Stegen JHG, Van der Veen AJ, Weerdenburg H, Hogendoorn JA, Versteeg GF (1999) Application of the Maxwell-Stefan theory to the transport in ion-selective membranes used in the chloralkali electrolysis process. Chem Eng Sci 54(13-14):2501-2511

3. Visser CR (2001) Electrodialytic recovery of acids and bases. Multicomponent mass transfer description. Rijksuniversiteit Groningen

4. Kraaijeveld G, Sumberova V, Kuindersma S, Wesselingh H (1995) Modelling electrodialysis using the Maxwell-Stefan description. Chem Eng J Biochem Eng J 57(2):163-176

5. Fila V, Bouzek K (2003) A mathematical model of multiple ion transport across an ion-selective membrane under current load conditions. J Appl Electrochem 33:675-684

6. Fíla V, Bouzek K (2008) The effect of convection in the external diffusion layer on the results of a mathematical model of multiple ion transport across an ion-selective membrane. J Appl Electrochem 38(9):1241-1252

7. Kodým R, Fíla V, Šnita D, Bouzek K (2016) Poisson-NernstPlanck model of multiple ion transport across an ion-selective membrane under conditions close to chlor-alkali electrolysis. J Appl Electrochem 46(6):679-694

8. Moshtarikhah S, de Groot MT, van der Schaaf J (2017) Nernst-Planck modeling of multicomponent ion transport in a Nafion membrane at high current density. J Appl Electrochem 47(1):51-62

9. Wesselingh JA, Krishna R (2000) Mass transfer in multicomponent mixtures, 1st edn. Delft University Press, Delft

10. Helfferich F (1962) Ion exchange. McGraw-Hill, New York

11. O'Brien TF, Bommaraju TV, Hine F (2005) Handbook of chloralkali technology volume I: fundamentals. Springer, Boston

12. Graham JS, Dranoff EE (1982) Application of the Stefan-Maxwell equations to diffusion in ion exchangers. 2. Experimental results. Ind Eng Chem Fundam 21:360-365

13. Krishna R (2016) Diffusing uphill with James Clerk Maxwell and Josef Stefan. Curr Opin Chem Eng 12:106-119

14. Verbrugge MW, Pintauro PN (1989) Transport models for ionexchange membranes. Compr Treatise Electrochem 19:1-67

15. Schlögl R (1956) The significance of convection in transport process across porous membranes. Z Phys Chem 21:46-52

16. Onsager L (1931) Reciprocal relations in irreversible processes. I. Phys Rev 37:406-426

17. Wesselingh JA, Vonk P, Kraaijeveld G (1995) Exploring the Maxwell-Stefan description of ion exchange. Chem Eng J Biochem Eng J 57(2):75-89

18. Chapman TW (1967) The transport properties of concentrated electrolytic solutions. University of California, Berkeley

19. Krishna R (1987) Diffusion in multicomponent electrolyte systems. Chem Eng J 35(1):19-24

20. Yeager HL (1980) Sodium ion diffusion in Nafion® ion exchange membranes. J Electrochem Soc 127(2):303

21. Yeager HL, O'Dell B, Twardowski Z (1982) Transport properties of Nafion membranes in concentrated solution environments. J Electrochem Soc 129(1):85-89

22. Yeager HL (1982) Transport properties of perfluorosulfonate polymer membranes. In: Eisenberg A, Yeager HL (eds) Perfluorinated ionomer membranes. American Chemical Society, Washington, DC, pp 41-63

23. Berzins $T$ (1978) Paper presented at the 71st annual meeting, American Institute of Chemical Engineers, pp. 12-16 
24. Førland KS, Førland T (1988) Irreversible thermodynamics: theory and applications. Wiley, New York

25. Strathmann H (2004) Ion-exchange membrane separation processes. Elsevier, Amsterdam

26. Wesselingh JA, Krishna R (1997) The Maxwell-Stefan approach to mass transfer. Chem Eng Sci 52(6):861-911

27. Yeo RS (1983) Ion clustering and proton transport in Nafion membranes and its applications as solid polymer electrolyte. J Electrochem Soc 130:533-538

28. Bandura AV, Lvov SN (2006) The ionization constant of water over wide ranges of temperature and density. J Phys Chem Ref Data 35(1):15-30

29. Higa M, Tanioka A, Miyasaka K (1988) Simulation of the transport of ions against their concentration gradient across charged membranes. J Membr Sci 37(3):251-266

30. Holz M, Heil SR, Sacco A (2000) Temperature-dependent selfdiffusion coefficients of water and six selected molecular liquids for calibration in accurate $1 \mathrm{H}$ NMR PFG measurements. Phys Chem Chem Phys 2(20):4740-4742

31. Hogendoorn JA, Van Der Veen AJ, Van Der Stegen JHG, Kuipers JAM, Versteeg GF (2001) Application of the Maxwell-Stefan theory to the membrane electrolysis process: model development and simulations. Comput Chem Eng 25(9-10):1251-1265

32. Bergner D, Hartmann M, Kirsch H (1989) Voltage-current curves: application to membrane cells. In: Modern chlor-alkali technology. Springer, Dordrecht, pp. 159-170

33. Grot W (2011) Fluorinated ionomers, 2nd edn. William Andrew, Oxford

34. Asahi Kasei Chemicals Corporation (2009) Recent development of Asahi Kasei chemicals' IM technology to reduce power consumption

35. Nidola A (1986) Zero gap membrane cell and SPE cell technologies vs. current density scale up. In: Membranes and membrane processes. Springer, Boston, pp 281-298

36. Chandran RR, Chin DT (1986) Reactor analysis of a chlor-alkali membrane cell. Electrochim Acta 31(1):39-50

Publisher's Note Springer Nature remains neutral with regard to jurisdictional claims in published maps and institutional affiliations.

\section{Affiliations}

\section{R. R. Sijabat ${ }^{1} \cdot$ M. T. de Groot ${ }^{1,2} \cdot$ S. Moshtarikhah ${ }^{1} \cdot$ J. van der Schaaf ${ }^{1}[$}

J. van der Schaaf

j.vanderschaaf@tue.nl

1 Eindhoven University of Technology, P.O. Box 513,

5600 MB Eindhoven, The Netherlands
2 Nouryon Industrial Chemicals, P. O. Box 75730, 1070 AS Amsterdam, The Netherlands 